\title{
Dynamic Fracture and Energy Evolution Characterization of Naturally Fractured Granite Subjected to Multilevel Cyclic Loads
}

\author{
Ning Guo, Changhong Li, Hao Liu, and Yu Wang \\ Beijing Key Laboratory of Urban Underground Space Engineering, Department of Civil Engineering, School of Civil \& \\ Resource Engineering, University of Science \& Technology Beijing, Beijing 100083, China \\ Correspondence should be addressed to Yu Wang; wyzhou@ustb.edu.cn
}

Received 27 December 2020; Revised 15 January 2021; Accepted 3 February 2021; Published 20 February 2021

Academic Editor: Feng Xiong

Copyright (c) 2021 Ning Guo et al. This is an open access article distributed under the Creative Commons Attribution License, which permits unrestricted use, distribution, and reproduction in any medium, provided the original work is properly cited.

\begin{abstract}
Naturally fractured rock mass is susceptible to stress disturbance and could result in the stimulation of natural fractures and even serious geological hazards. In this work, multilevel uniaxial fatigue loading experiments were carried out to reveal the fracture and energy evolution of naturally fractured granite using stress-strain descriptions and energy evolution analysis. Results reveal the influence of natural fracture on mechanical properties of granite, regarding the fatigue lifetime, fatigue deformation characteristics, fatigue damage, energy evolution, and fatigue failure pattern. Volumetric and shear processes caused by the sliding and shearing along the natural fracture control the whole failure process. The energy dissipation and release characteristics are strongly impacted by natural fractures. The elastic energy and dissipated energy both decrease with increasing natural fracture volume, growth of the dissipated energy becomes faster for rock near to failure. It is proved that the dissipated energy is mainly used to activate the preexisting natural fractures.
\end{abstract}

\section{Introduction}

Most of the engineering and environmental loads applied to the rock mass are cyclic loads. For example, the tides, earthquakes, and volcanic eruptions are natural phenomenon closely related to cyclic loading conditions; in addition, human-induced activities like mining activities [1, 2], hydraulic fracturing, traffic loading [3], or gas storage $[4,5]$ can be also categorized as cyclic loading essentially. Under practical engineering conditions, it is inevitable that rocks are disturbed by various cyclic loads, which can lead to certain fatigue damage or even failure of the rock. As a result, characterization of the fatigue mechanical properties and failure mechanism of rock subjected to fatigue loading conditions is crucial to ensure the long-term stability of rock structures in mining or civil engineering.

A large number of experimental investigations have documented the fatigue mechanical properties of rock. Rock physical and mechanical properties, e.g., stiffness [6], strength $[7,8]$, elastic modulus $[9,10]$, or ultrasonic pulse velocity [11], decrease for rock under cyclic and fatigue load- ing conditions. Deterioration of rock mechanical properties is the external reflection of damage accumulation inside the rock, and many different kinds of damage factor defined by ultrasonic velocity, rock density, and energy density have been studied. In addition, it is accepted that the factors of loading frequency, loading waveform, and stress amplitude are the main factors impacting the fatigue behavior of rock, and numerical experiments have been performed to reveal the influence of those factors on fatigue characteristics of rock [12-15]. Fatigue/cyclic loading can load the rock at levels below the peak rock strength principal and can also lead to rock failure, mainly because of the accumulation of plastic deformation and/or postcyclic failure cycles. From reading the literature, the effect of cyclic loading on rocks containing natural fractures has been little studied and most of the studies have focused on intact rocks.

In addition, many scholars have considered constant amplitude loads on rocks in uniaxial or triaxial stress states at different frequencies, but in practical engineering of mining and civil engineering, rocks are always disturbed by stresses such as blasting, vibration, and mechanical 


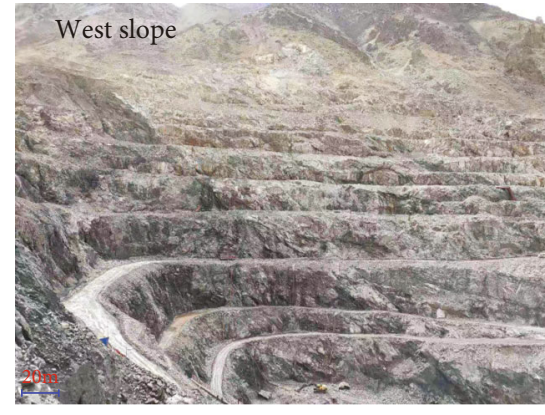

(a)

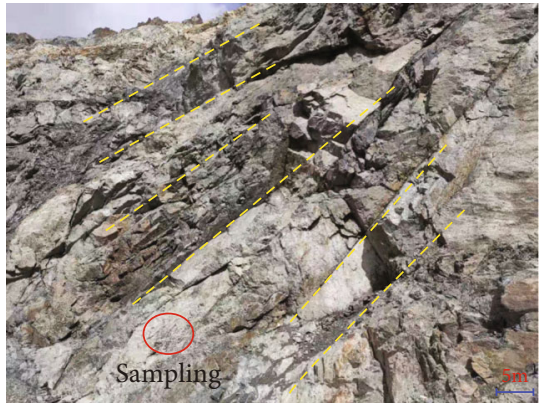

(b)

FIGURE 1: Rock mass structure of the Beizhan open pit slope, a set of dominant structural plane can be observed as drawn in orange color.

excavation [16, 17], and the forms of loads acting on rocks are multilevel. For example, in railroads or roads, the increase or decrease in the number of vehicles affects the amount of loading, and the cyclic loading is multilayered. In underground mining, the impact from blasting is also multilayered; in slope production, the periodic loads carrying geological disturbances are also multilayered.

Numerous studies at home and abroad have shown that the destruction of rocks is due to energy damage, and energy dissipation and release fracture have been widely studied in the scientific community [18-21]. Zhao et al. [22] used $\mathrm{RFPA}^{2 \mathrm{D}}$ to study the damage behavior of rock specimens, including damage processes, damage modes, damage mechanisms, and shear strength. Zhang et al. [23] performed rock damage model process analysis (RFPA) simulations and count fractal analysis to investigate the effect of interfracture density on the shear fracture and fractal properties of rock bridges in jointed rocky slopes. Bai et al. [24] presented an experimental study of the dynamic compressive behavior of concrete confined with unidirectional natural flax fiberreinforced polymers (FFRPs) under axial impact loading. A new dynamic strength model was also proposed to predict the dynamic compressive strength of FFRP-confined concrete in the studied strain rate range. Wang et al. [25] determined the type I (open mode) dynamic fracture toughness of rocks by affixing strain gauges to Brazilian disc (CSTBD) samples with cracks on the sample surface and subjecting them to the radial impact of a Hopsonkin separator. Wang et al. [26] conducted an experimental study on the mechanical and energetic properties of granite under dynamic triaxial loading and investigated the effects of impact velocity and enclosure pressure on the stress-strain curve response, dynamic strength, plastic deformation, energy loss, and damage mode of granite. Wong et al. [27] investigated, through uniaxial compression tests, the friction of rock-like fracture materials with different fracture dip angles, different dip bridges, and different fracture contact surfaces. The crack closure and strength characteristics of rock-like fracture materials with different crack inclination angles, different inclination bridges, and different frictional characteristics of the crack contact surface were studied by Wong et al. [27], who classified the crack extension and closure into three modes, shear (S-mode), mixed tensile-shear (M-mode), and winged tensile damage (W-mode). Li et al. [28] found that the evolution of energy of rocks can be divided into three stages by studying the energy evolution and fatigue behavior of sandstone under cyclic loading: fatigue hardening stage (I), stable development stage (II), and steep damage stage (III). Erarslan and Williams [29] used both sinusoidal cyclic loading and cyclic with increasing average level to load the tuffs and studied the energy changes of different loading on rock damage. From these studies, it can be seen that previous studies were based on constant fatigue loading rather than on the energy variation under different loading conditions at multiple stages.

Based on the above discussions, in this work, multilevel uniaxial fatigue loading experiments were performed using a GCTS rock testing system for granite samples containing natural fractures. The tested rock was obtained from an open pit slope located at the Hejing Beizhan iron mine in Xinjiang province, northwest of China. Based on the experimental data, the macroscopic stress-strain responses, dynamic elastic modulus, damping ratio, and damage evolution were systematically studied; in addition, energy evolution during different fatigue loading stages was also investigated to clarify the energy dissipation and release during sample deformation.

\section{Equipment and Test Scheme}

2.1. Tested Rock Material Descriptions. The tested rock material was obtained from an open pit slope at the Hejing Beizhan iron mine in Xinjiang province, northwest of China. The rock slope is mainly composed of naturally fractured granite, a set of dominant structural plane can be clearly observed on the slope, which controls the stability of the open pit slope, as shown in Figure 1. The rock mass structural plane has an inclination of $290^{\circ}$ and a dip angle about $70^{\circ}$.

The core containing natural fractures was drilled into a cylinder with a diameter $(D)$ of $50 \mathrm{~mm}$ and a height $(H)$ of $100 \mathrm{~mm}$ and ground flat within $\pm 0.1 \mathrm{~mm}$ according to the method recommended by ISRM. The tested samples were oriented in the structural plane parallel to the natural rock structure plane and contained natural fractures inside. The natural fracture scheme of the granite samples is shown in Figure 2. Typical samples are labeled as NFG1, NFG3, NFG5, and NFG7, corresponding to natural fracture volume ratios $\left(R_{\mathrm{v}}\right.$, defined as the ratio of total natural fracture volume 

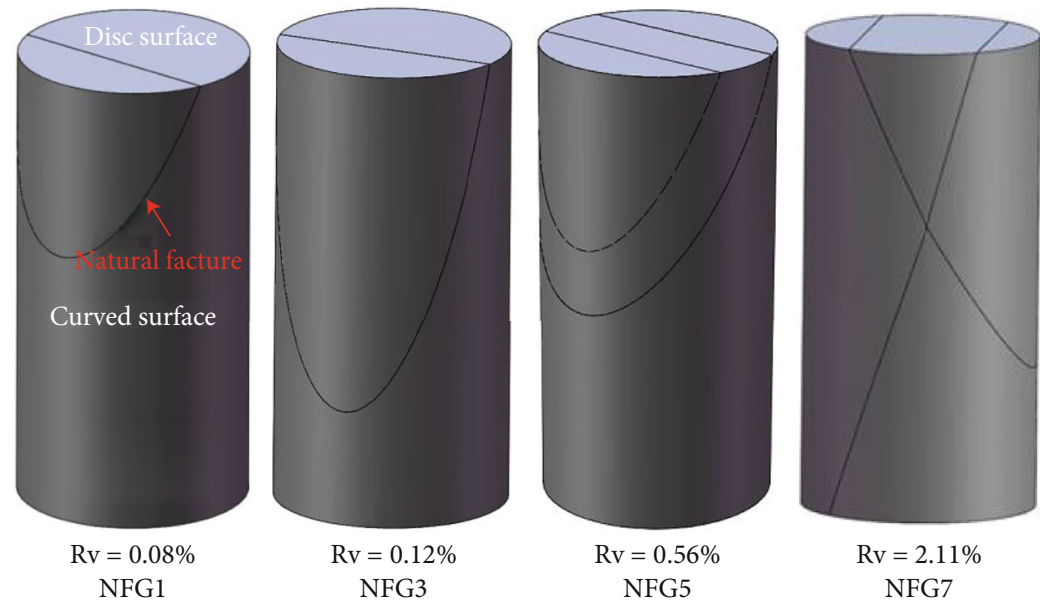

FIGURE 2: Scheme of natural fractures on granite samples used in the multistage fatigue loading test, the natural fractures are schemed in black color on the curved surfaces and disc surface.

to sample volume) of $0.08 \%, 0.12 \%, 0.56 \%$, and $2.11 \%$, respectively. By observing the fractures on the rock surface, one inclined natural fracture was observed on samples NFG1 and NFG3, and two natural fractures were observed on samples NFG5 and NFG7. The fractures on sample NFG7 showed an "X" shape. CT scans were performed to detect the initial damage characteristics, followed by fatigue mechanics experiments.

2.2. Testing Equipment. The rock samples were subjected to multilevel fatigue loading tests using a servo-hydraulically controlled rock mechanics test rig (GCTS RTR 2000). Axial and circumferential strain LVDT devices were installed on the sample surface to monitor the entire deformation process. The tester enables dynamic loading frequencies from 0 to $10 \mathrm{~Hz}$, with axial strain, axial stress, and lateral strain recorded by a central computer at the same sampling frequency.

2.3. Testing Procedure and Scheme. Granite samples containing different natural fracture volumes were subjected to multistage uniaxial cyclic loading tests using stress control mode, and cyclic loading with specified stress amplitude of $10 \mathrm{MPa}$ was applied to set the initial damage levels of granite samples to $0.08 \%, 0.12 \%, 0.56 \%$, and $2.11 \%$, respectively. A sinusoidal cyclic compression load in the axial direction was applied, and loading and unloading were performed once in $2 \mathrm{sec}-$ onds. The average stress was increased by $10 \mathrm{MPa}$ per cycle, and the samples were cyclically loaded for 30 cycles. The fatigue loading was completed until all samples finally failed. Detailed description of the cyclic loading path can be found in Wang et al. [9].

2.4. Method to Damage and Energy Evolution. In order to characterize the changes of stress hysteresis loop, two parameters of dynamic elastic modulus $\left(E_{\mathrm{d}}\right)$ and damping ratio $\left(D_{\mathrm{r}}\right)$ are employed according to the studies of Wang et al. [30] and Lamas-Lopez [31]. The detailed definitions of these two parameters can be found in the studies of Wang et al. [31]. In addition, a damage factor defined by axial strain was intro- duced to quantitatively reveal the damage deterioration process of two-defective granites during the fatigue loading phase. Previous studies have shown that the variation of axial strain under fatigue loading conditions is a good predictor of damage propagation and fatigue life prediction $[15,32,33]$. Therefore, to better evaluate the damage evolution process of rocks under fatigue loading, the damage factor of the maximum axial strain was used for evaluation. In general, considering the strain-equivalent mechanism of continuous damage mechanics, a one-dimensional damage constitutive equation has been proposed $[15,32,33]$. According to the definition of the damage index by Wang et al. [15], the characteristics of the damage evolution under fatigue loading were analyzed.

Assuming that the test system is a closed system with no heat exchange with the outside world during the test, the relationship between the total input energy, elastic energy, and dissipation energy of the rock can be expressed according to the first law of thermodynamics and the study by Solecki and Conant [34]. The definition of the energy conversion during rock failure has been studied by Solecki and Conant [34] and Hai et al. [21]. As damage and fracture of rock are energy driven, the dissipation energy is due to the damage of the rock structure, such as initiation, propagation, and coalescence of cracks [13].

\section{Experimental Result Analysis}

3.1. Represented Cyclic Stress-Strain Responses. The loading path and the associated complete stress-strain curves for the granite samples containing different natural fracture volume are cited from the previous studies of Wang et al. [9], and they are shown in Figure 3. It can be seen that the preexisting natural fracture impacts the fatigue lifetime of granite. Under the sample loading method, the fatigue loading stage is $7,5,3$, and 2 , respectively. The corresponding loading cycle number is $210,150,90$, and 60 , respectively. The fatigue strength is influenced by the natural fracture volume in rock samples; it is $78.40,63.55,44.50$, and $26.51 \mathrm{MPa}$, respectively. The plasticity deformation is relatively large due to the 
(a1)

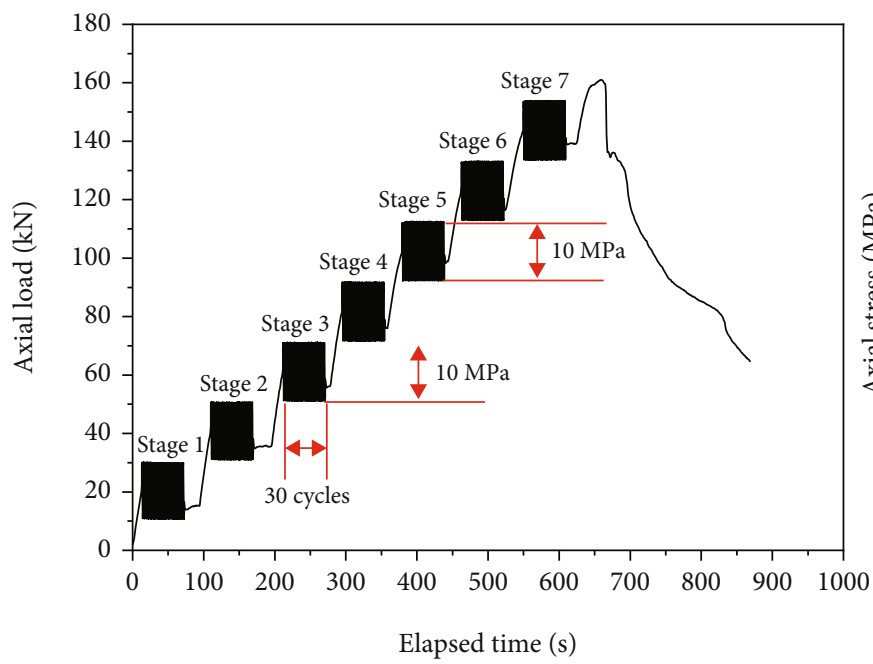

Axial load

(a)

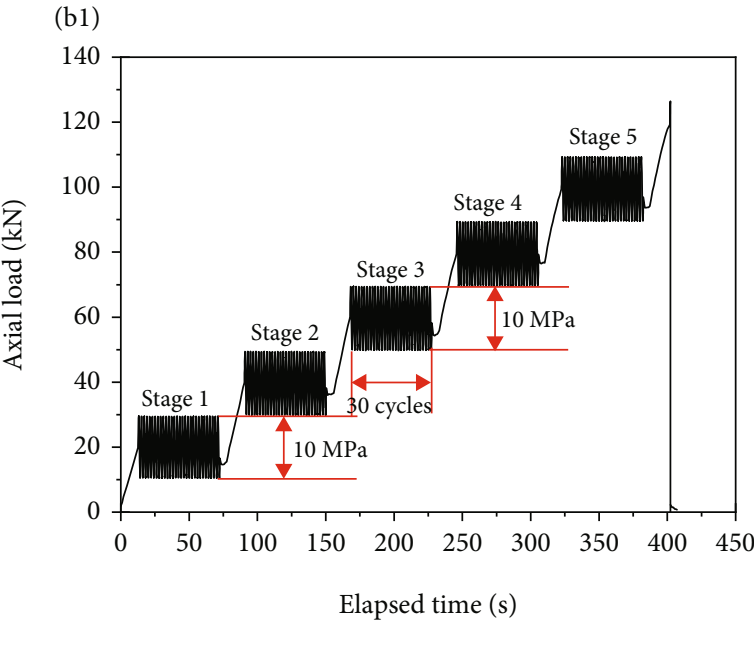

(a2)

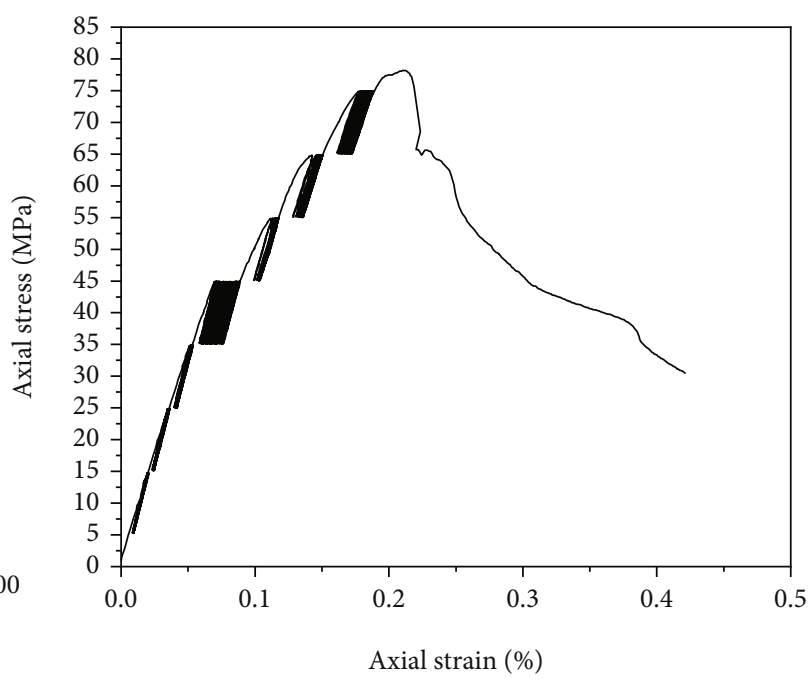

_ Ea-axial strain

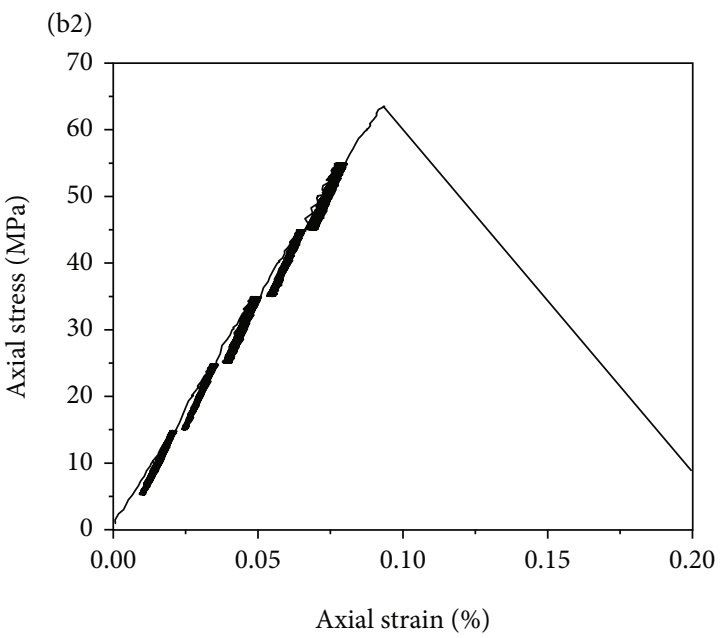

_ Ea-axial strain

(b)

Figure 3: Continued. 


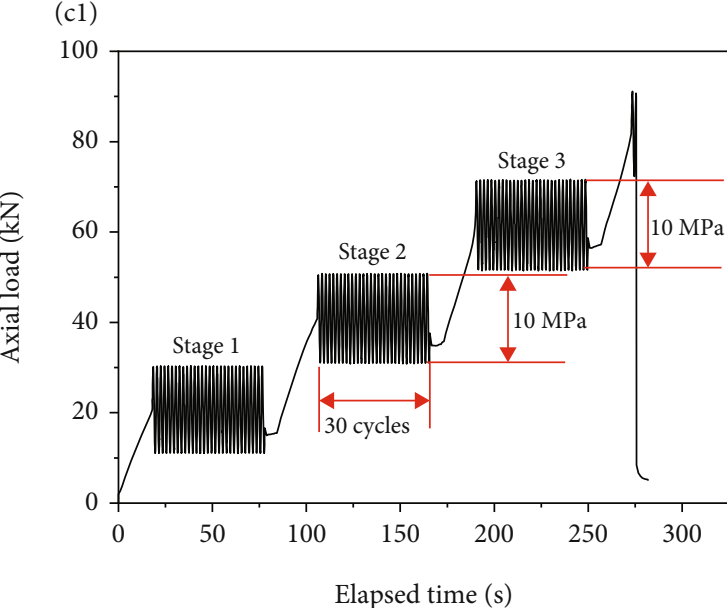

— Axial load

(d1)

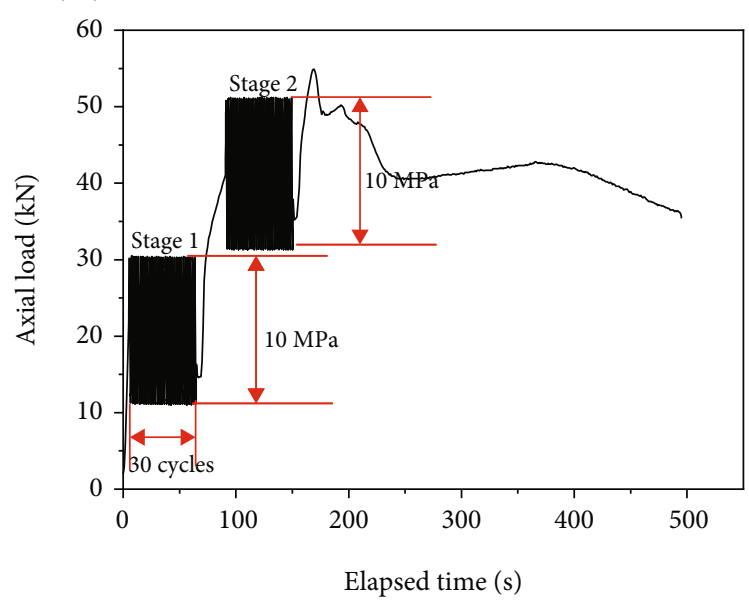

_ Axial load

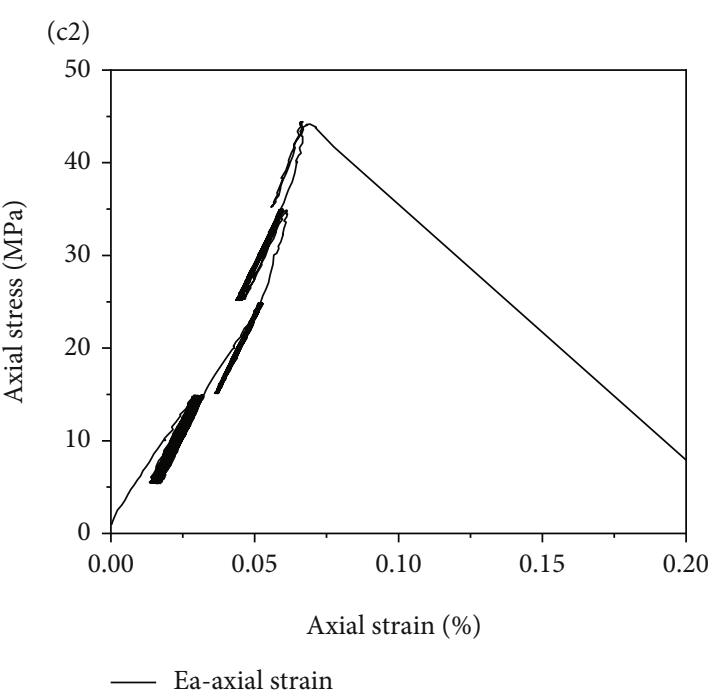

(c)

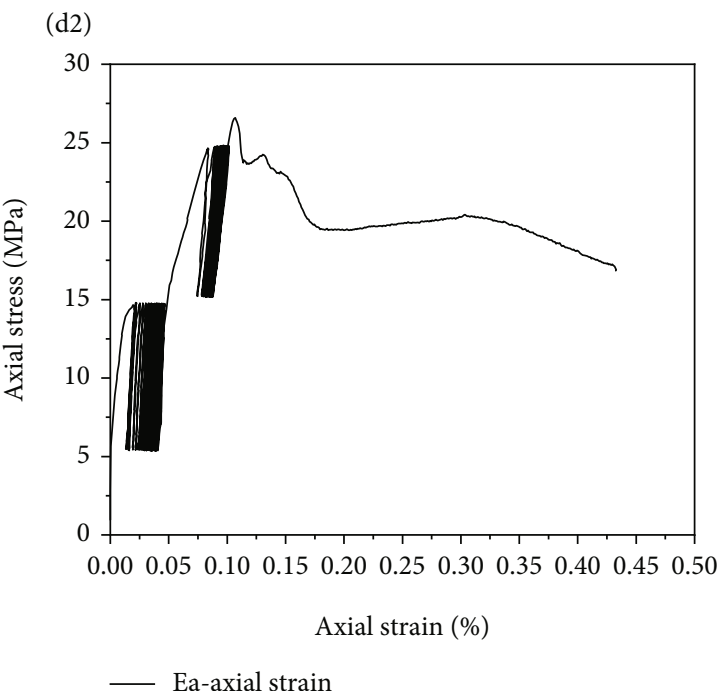

(d)

FIGURE 3: The loading path and axial stress-strain curves for the granite samples with natural fractures. (a-d) The natural fracture volume ratio is $0.08 \%, 0.12 \%, 0.56 \%$ and $2.11 \%$, respectively.

existence of natural fracture inside the samples; the hysteresis loop forms at low stress level. The peak strain is different for the tested samples, which is related to the rock fatigue failure mode; it is $0.21 \%, 0.09 \%, 0.06$, and $0.11 \%$, respectively. It can be seen that failure of the typical tested samples all occurs at the stress-increasing stage, indicating that damage at the stress-increasing stage is larger than the fatigue loading stage. Fatigue failure mode is different which can be observed from the stress-strain curve morphology. For the sample of NFG1 and NFG7, they gradually fail with experimental time; however, abrupt failure occurs for the samples NFG3 and NFG5, and the stress-strain curve presents a sudden drop pattern.

Since the volumetric strain is a comprehensive reflection of the specimen deformation, the volumetric stress-strain curve can better reflect the overall deformation of the specimen. Under the influence of natural fractures, the volume of NFG7 natural fractures is the largest and expands at the beginning of loading. But for the other three samples of NFG1, NFG3, and NFG5, their capacity underwent a process of first compression and then expansion. At each fatigue loading stage, the morphology of hysteresis loop changes from sparse to dense. The hysteretic sparse pattern is caused by the sudden increase of axial stress. The results show that the damage degree of the rock is serious in each stress increasing stage, and the deformation amount is relatively small in the fatigue loading stage.

3.2. Fatigue Volumetric Evolution Analysis. Rock deformation grows as loading cycle increases, and the incremental rate is impacted by the loading stages and the initial natural fracture scale. Figure 4 plots the relationship between the axial, lateral, and volumetric strain against the experimental time. It can be seen that deformation steadily increases 


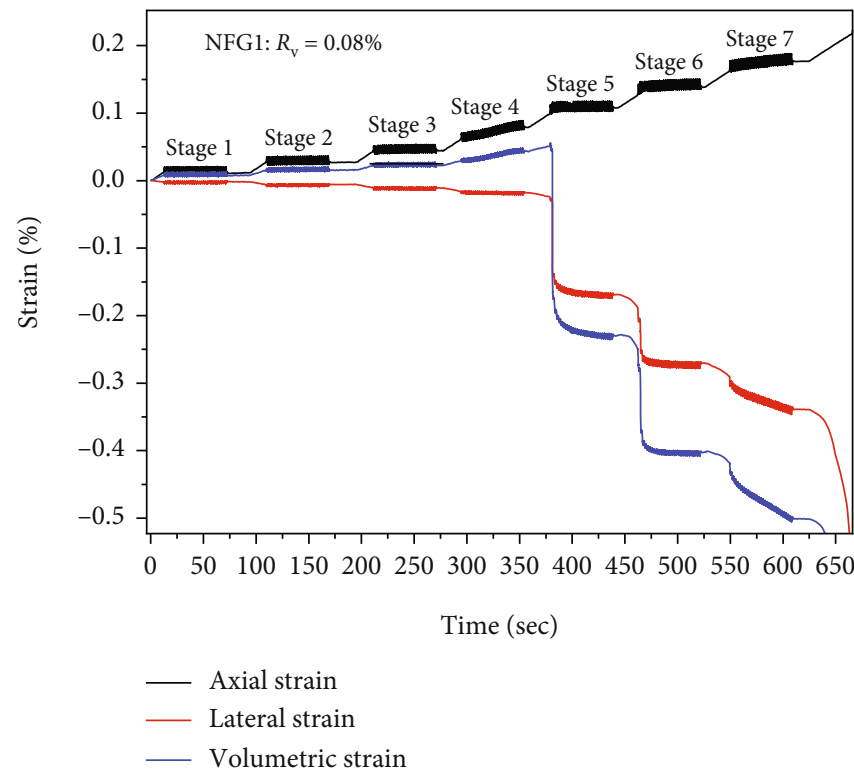

(a)

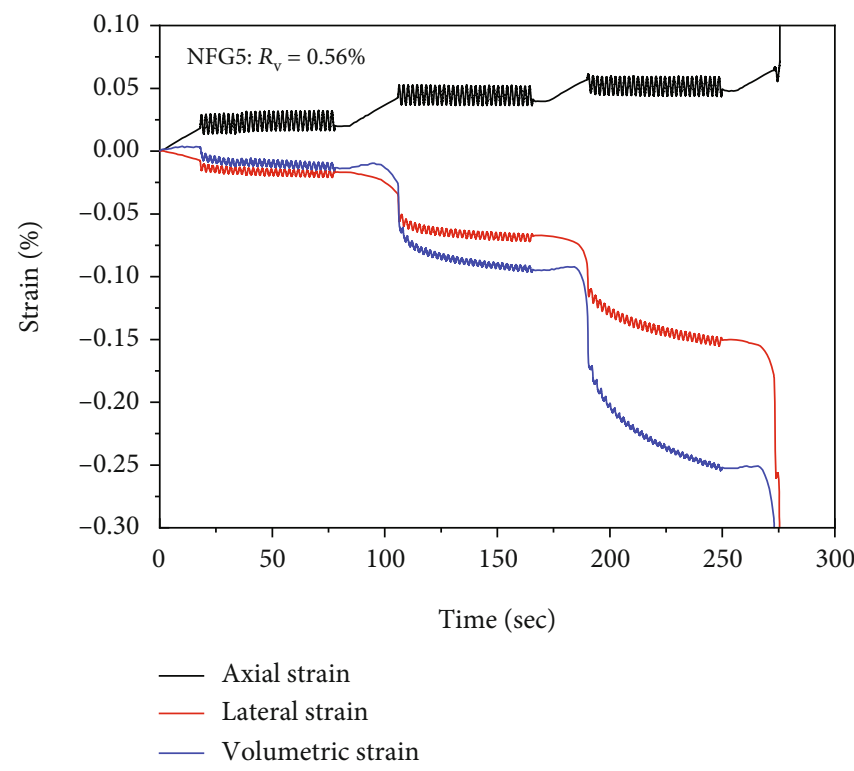

(c)

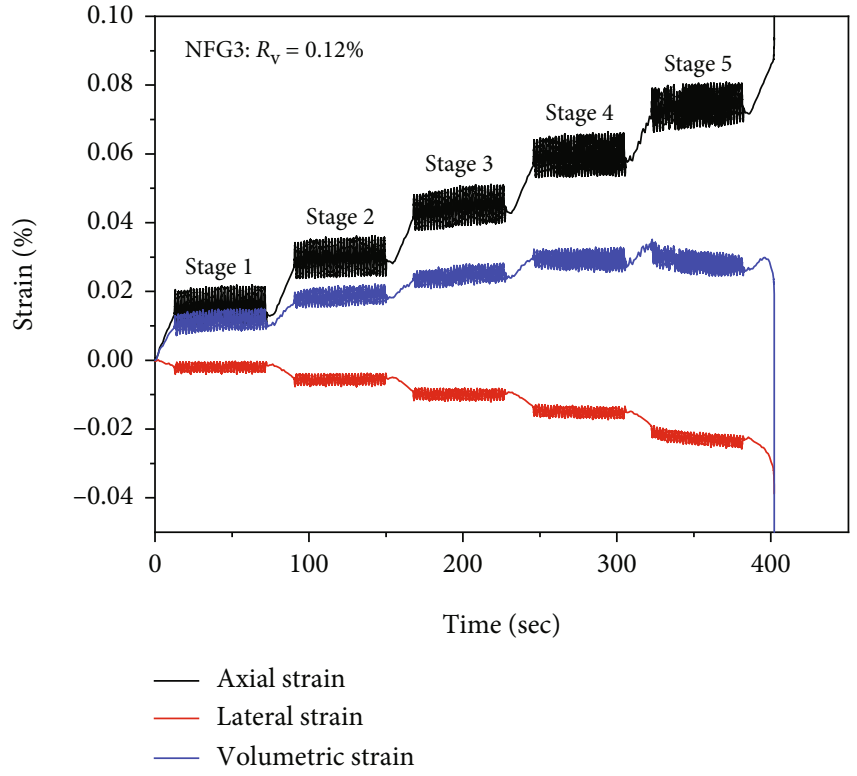

(b)

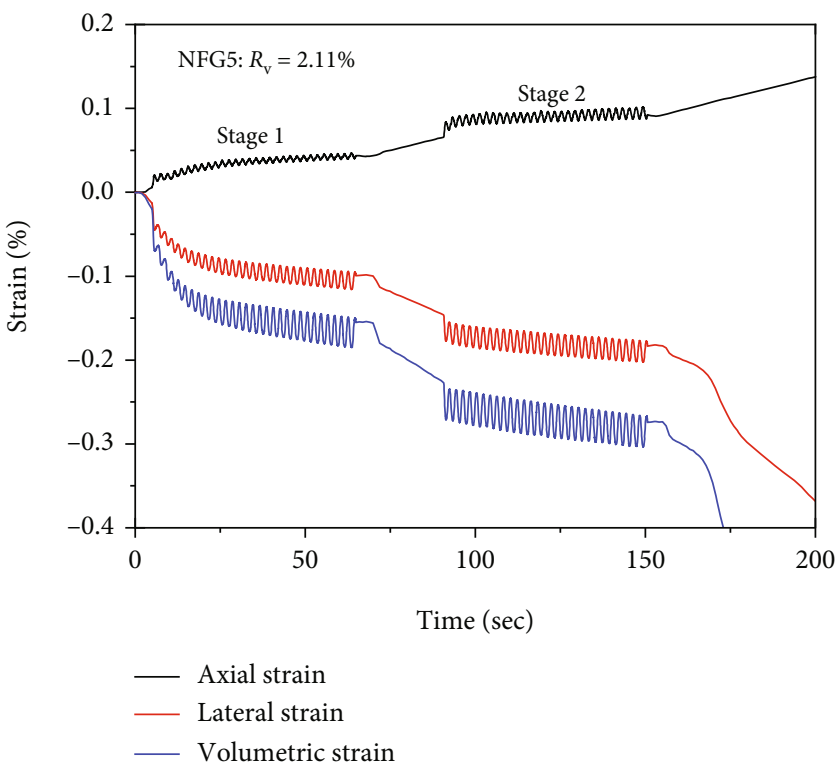

(d)

FIGURE 4: Fatigue deformation characteristics of the tested granite samples containing different natural fracture volumes. (a-d) The natural fracture volume ratio is $0.08 \%, 0.12 \%, 0.56 \%$, and $2.11 \%$, respectively.

within a fatigue loading stage; however, it grows faster a certain loading stage. The onset of deformation accelerating increment corresponds to different loading stages, indicating the influence of natural fracture on the stress dilatancy of granite. The accelerated growth stage is $4,3,2$, and 1 , respectively. For sample NFG7, the sample volume expands at the first loading stages when loading acts on the sample, and deformation grows faster and faster until failure. For the other samples, the sample volume first decreases due to the compression of the preexisting natural fractures and then increases when fractures are stimulated again. The final volumetric strain is the maximum for NFG1 and minimum for NFG3; this is related to the fatigue failure mode. Accelerated growth of deformation implies the damage accumulation resulting from the initiation of the preexisting natural fracture and the interaction between them and the new stimulated fractures.

3.3. Characterizations of $E_{d}$ and $D_{r}$. To describe the evolution of stress hysteresis loop during sample deformation and reveal the impact of the initial natural fracture volume on the damage evolution, two dynamic indices of dynamic elastic modulus and damping ratio are analyzed in Figure 5. Figures 5(a)-5(d) plot the relationship between the dynamic elastic modulus and loading cycle number. Interestingly, the $E_{\mathrm{d}}$ cycle curve presents different changing trends for the 


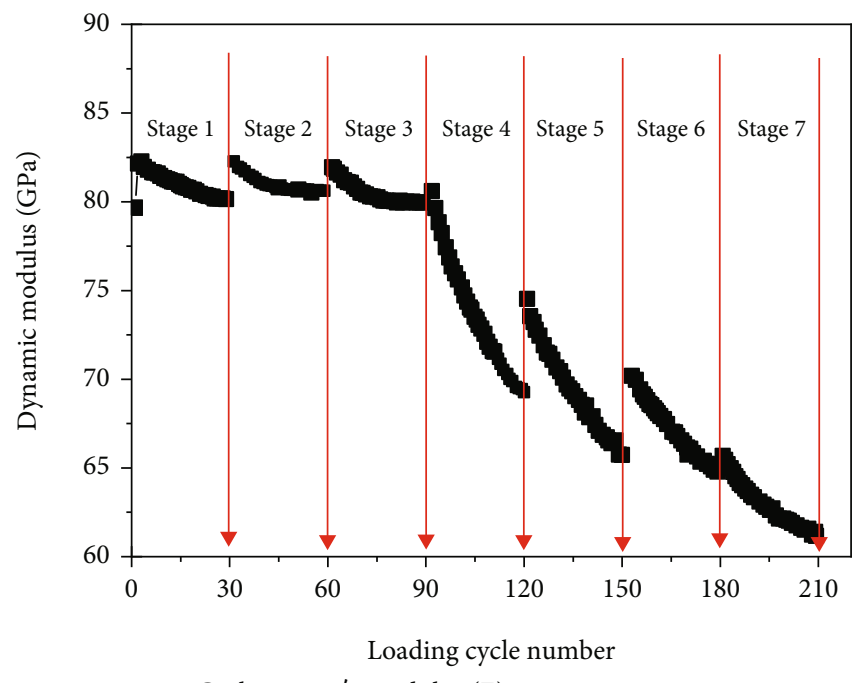

-- Cyclic young's modulus (E)

(a)

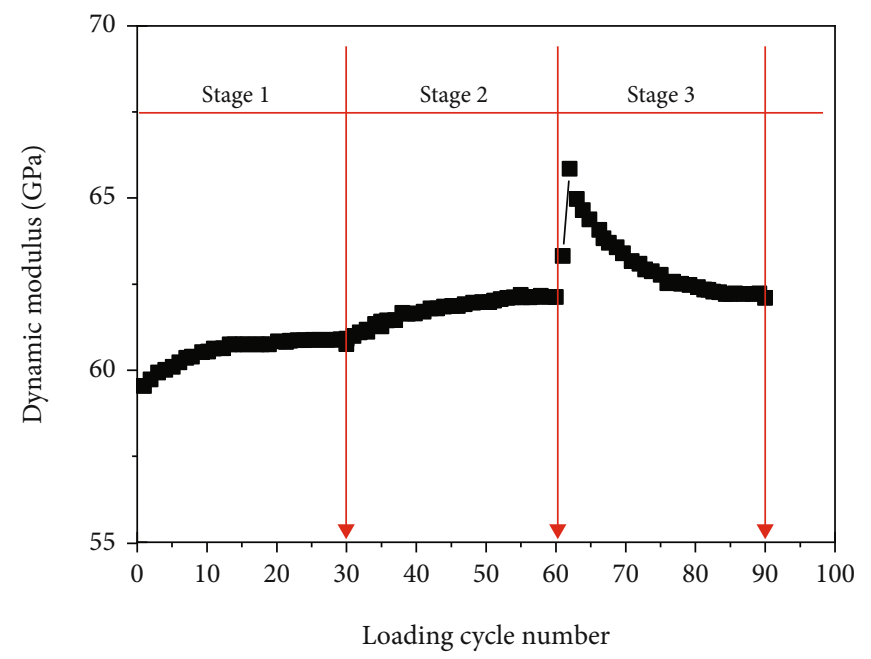

-a- Cyclic young's modulus (E)

(c)

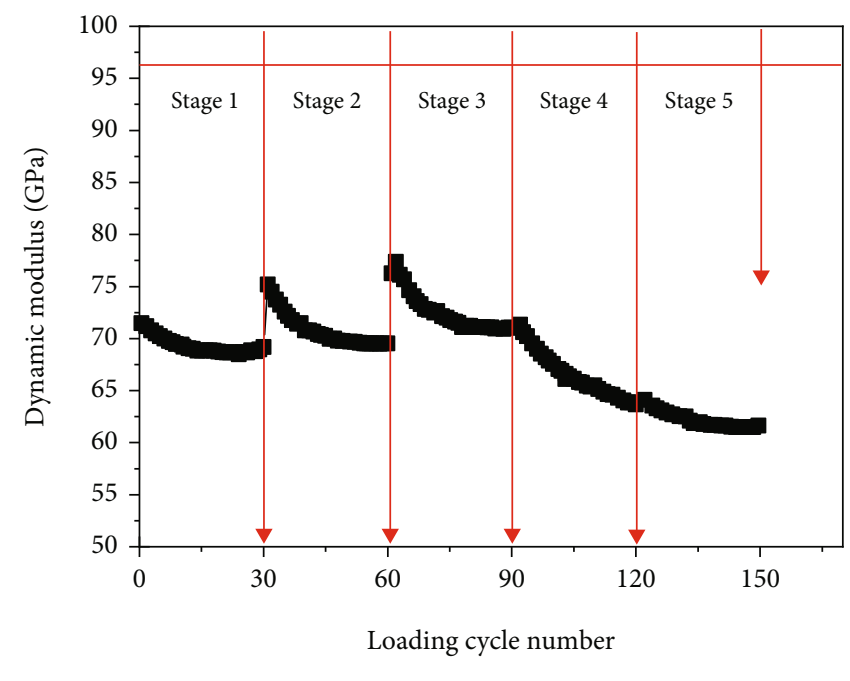

-- Cyclic young's modulus (E)

(b)

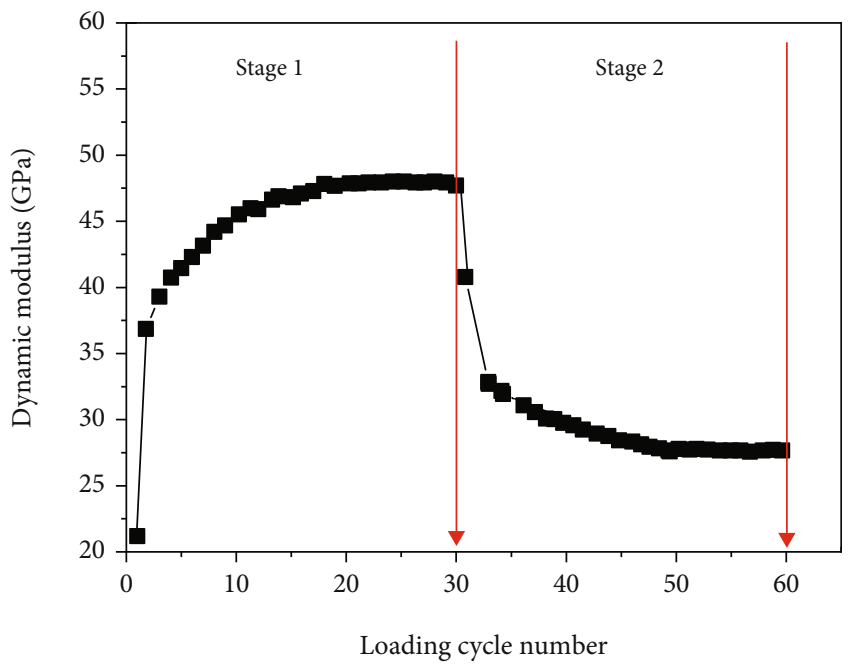

-a- Cyclic young's modulus (E)

(d)

Figure 5: Continued. 


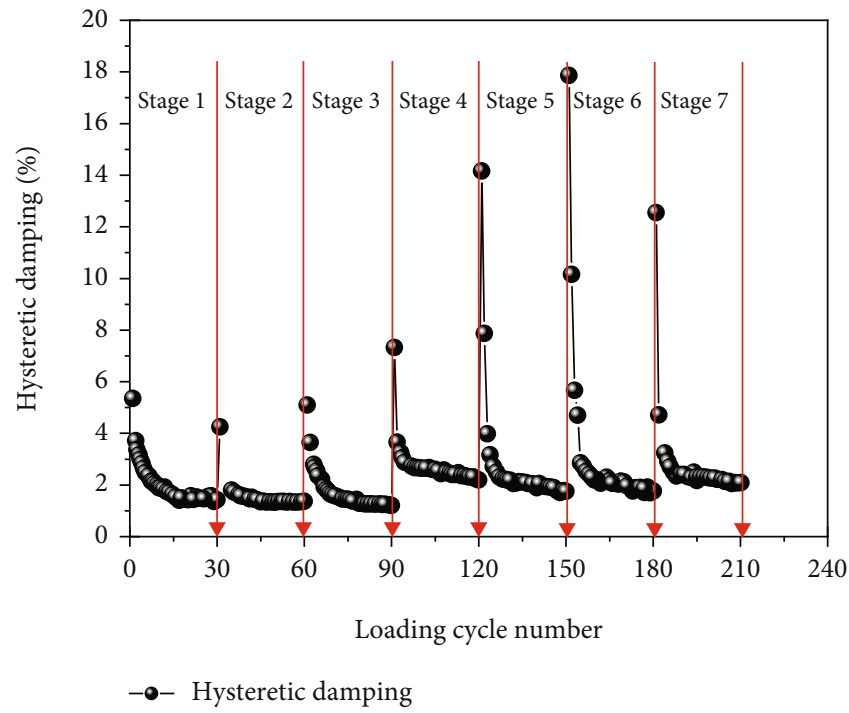

(e)

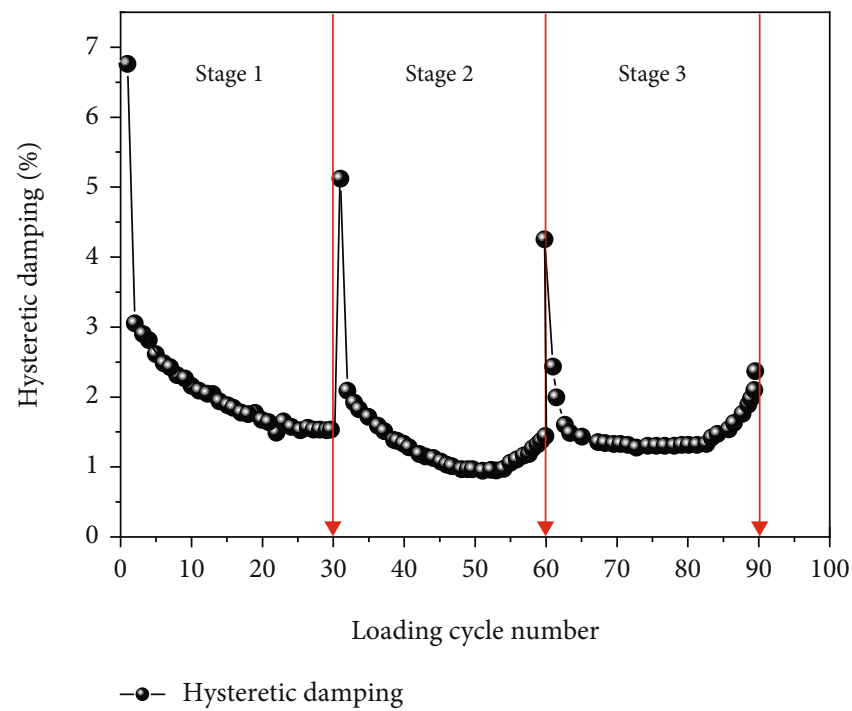

(g)

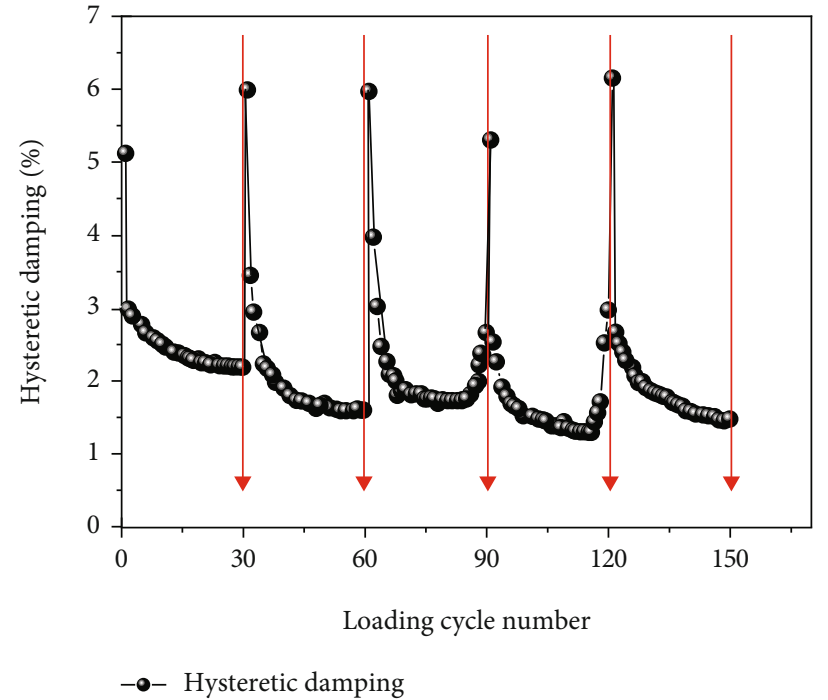

(f)

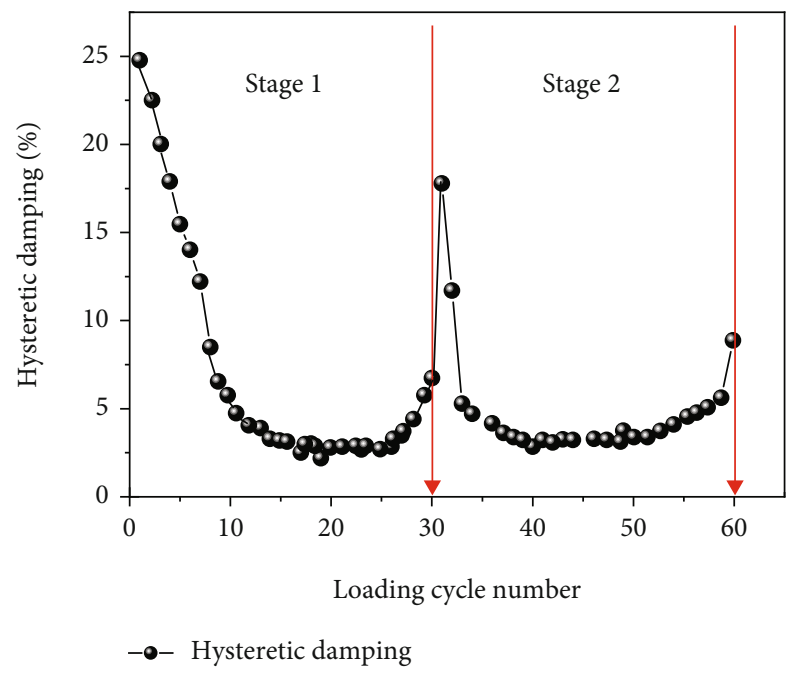

(h)

Figure 5: Evolution of the dynamic elastic modulus $\left(E_{\mathrm{d}}\right)$ and hysteretic damping ratio $\left(D_{\mathrm{r}}\right)$ with cyclic number for sample with natural fracture volume ratio of $0.08 \%, 0.12 \%, 0.56 \%$, and $2.11 \%$, respectively. (a-d) Plots of $E_{\mathrm{d}}$ against loading cycle number during sample deformation; (e-f) plots of the $D_{\mathrm{r}}$ against loading cycle number during sample deformation.

tested samples. For NFG1 and NFG3, $E_{\mathrm{d}}$ first decreases and increases within a loading stage for the first three loading stages; and then, it decreases monotonously until the last loading cycle. $E_{\mathrm{d}}$ presents an overall decreasing trend, and the decreasing rate becomes faster with increasing loading cycles. However, for NFG5 and NFG7, $E_{\mathrm{d}}$ increases before the last fatigue loading stage and it decreases at the last loading stage. The increasing of $E_{\mathrm{d}}$ indicates the compaction of natural fractures, and the rock stiffness improves; decreasing of $E_{\mathrm{d}}$ indicates the growth of accumulative damage. The change of $E_{\mathrm{d}}$ implies the compaction and opening of the preexisting fractures and the formation of new fractures.

The evolution of $D_{\mathrm{r}}$ with loading cycle is presented in Figures $5(\mathrm{e})-5(\mathrm{~h}) . D_{\mathrm{r}}$ reflects the energy loss during rock deformation; the evolution of $D_{\mathrm{r}}$ is influenced by the preex- isting natural fracture volume. Within a fatigue loading stage, $D_{\mathrm{r}}$ first decreases and then increases; $D_{\mathrm{r}}$ shows an overall first decreasing and increasing trend during sample deformation. It can be seen that $D_{\mathrm{r}}$ decreases sharply at the onset of each fatigue loading stage; this indicates that the hysteresis loop changes from sparse to dense. This result is consistent with the result in the stress-strain responses. The sudden stress increasing results in the larger damage in rock, preexisting natural fracture slides and then they are closed under fatigue loading. Accompanying the damage accumulation inside the granite samples, $D_{\mathrm{r}}$ shows an increasing trend, indicating that the dissipated energy used to drive damage propagation increases accordingly.

In order to well describe the influence of the preexisting natural fracture on the evolution of hysteresis loop, 


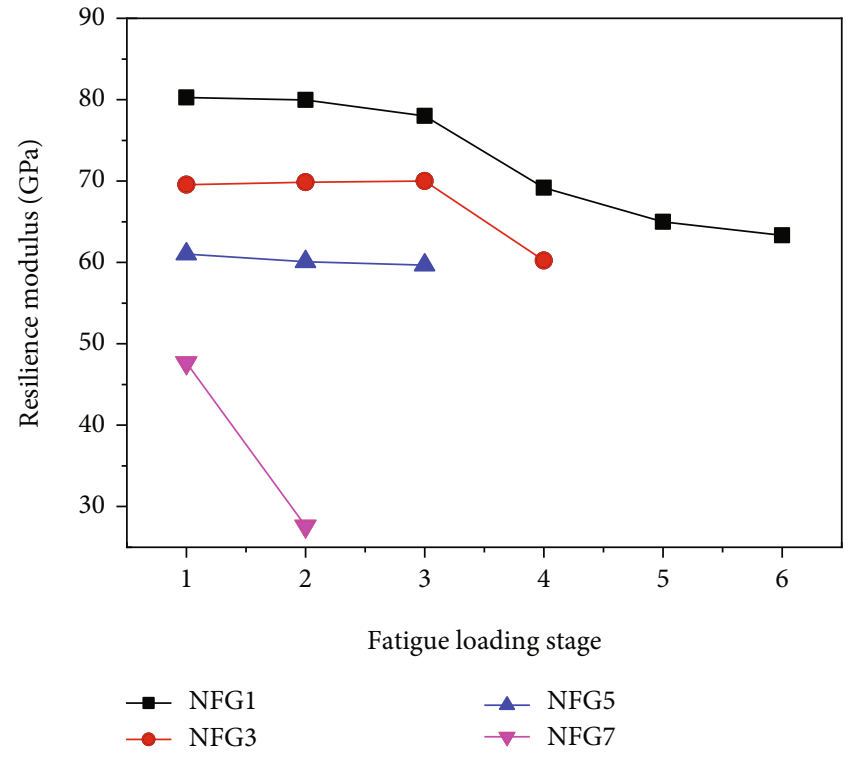

(a)

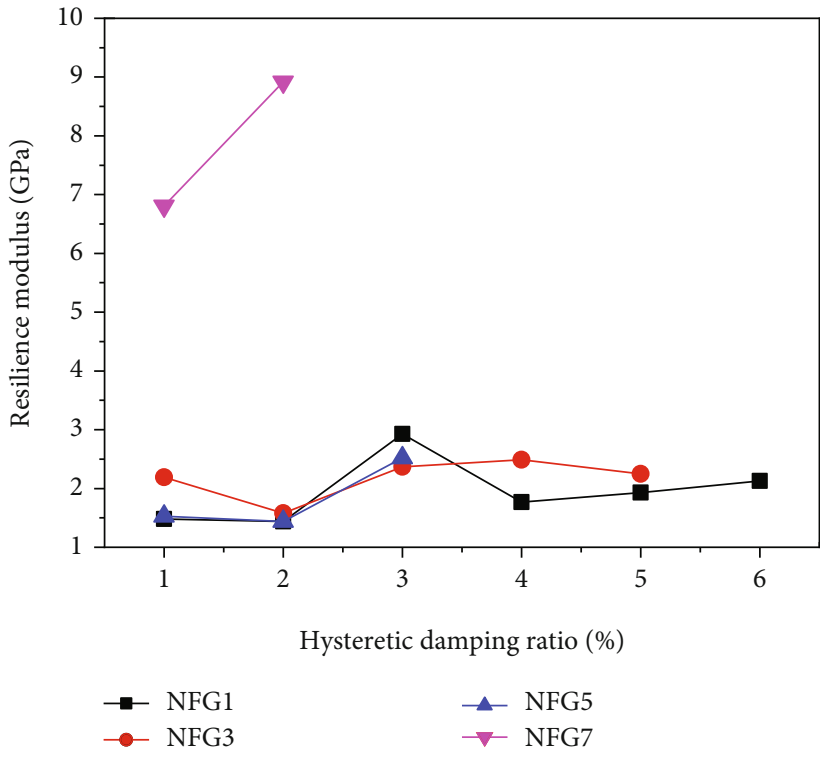

(b)

Figure 6: Comparison of the (a) dynamic elastic modulus and (b) damping ratio for the samples with different natural fracture volume ratios.

Figure 6 shows the relationship between the dynamic elastic modulus $\left(E_{\mathrm{d}}\right)$, damping ratio $\left(D_{\mathrm{r}}\right)$, and fatigue loading stage. In Figure $6(\mathrm{a})$, it can be seen that $E_{\mathrm{d}}$ decreases with the increase of natural fracture volume. It is the maximum for sample NFG1 and minimum for sample NFG7. In Figure $6(\mathrm{~b}), D_{\mathrm{r}}$ presents fluctuation trend as fatigue loading stage grows. This result indicates the complexity of hysteresis loop evolution; the pattern of hysteresis loop is influenced not only by the applied fatigue loading but also the preexisting natural fractures. For sample NFG7, it has the largest natural fracture volume, and $D_{\mathrm{r}}$ is relatively high than other cases. This result indicates that the energy input used to drive the evolution of damage is relatively larger, and the plastic deformation for this sample is also larger than that for other samples.

3.4. Fatigue Damage Evolution Analysis. Using Equation (9), the damage evolution is shown in Figure 7. For the four tested samples, the evolution of damage factor in Figures $7(\mathrm{a})-7(\mathrm{~d})$ shows a step increasing trend, and the increasing rate is different during the whole deformation. The damage factor increases quickly at the first several fatigue loading stages, and then, the increasing rate decreases. This result implies that the influence of preexisting natural fractures is greater than the newly formed fractures. Deformation caused by the sliding and shearing along the natural fracture controls the whole damage evolution process. Within a fatigue loading stage, damage grows faster for the sample NFG7 than the samples NFG1, NFG3, and NFG5. Interesting is that the damage factor increases to 0.75 after the first fatigue loading stage; the first fatigue loading stage almost controls the fatigue lifetime of the sample. The effect of natural fractures on damage evolution is plotted in Figure $7(\mathrm{e})$. This figure clearly presents the differential damage characteristics due to the existing natural fractures. Dam- age factor is the largest for sample NFG7 and smallest for sample NFG1. Influenced by the preexisting natural fractures, the damage growth trend becomes steady with increasing fatigue loading stages. The compaction and sliding of natural fracture are the main factors resulting in the failure of granite sample.

3.5. Energy Evolution during Sample Deformation. As the fracture evolution of rock is strongly related to the energy dissipation and release, we plot the relationship between total energy $U$, elastic energy $U_{\mathrm{e}}$, dissipated energy $U_{\mathrm{d}}$, and relative cycle $(n / N)$ in Figures $8(\mathrm{a})-8(\mathrm{~d})$. At the first several fatigue loading stages, it can be seen that input energy stored as elastic energy in granite samples, the differences between $U$ and $U_{\mathrm{e}}$ are small. $U_{\mathrm{d}}$ in the initial stage of fatigue loading is due to the compaction of natural fractures; the proportion of $U_{\mathrm{d}}$ is relatively small. With the increases of fatigue loading, most of the input energy transfers into dissipated energy; the dissipated energy is used to activate the preexisting natural fractures and stimulate new fractures. As the cyclic loading continues, the preexisting natural fractures are totally compacted. The elastic energy $U_{e}$ that can be released in rock increases quickly than the dissipated energy $U_{\mathrm{d}}$. The increment of dissipated energy is steady and increasing rate is relatively small; this is influenced by the natural fracture. The reason of this result is that fracturing of rock is slow because of the sliding of main fracture plane along the natural fractures, and most of the dissipated energy is used to reactivate the natural fractures. At the last few fatigue loading stages, it can be clearly observed that the difference between $U$ and $U_{\mathrm{e}}$ becomes larger accordingly. The relationships between $U$, $U_{\mathrm{e}}, U_{\mathrm{d}}$, and the natural fracture volume ratio $R_{\mathrm{v}}$ are further studied, as shown in Figures 8(e) and 8(f). The fitting results show that $U, U_{\mathrm{e}}$, and $U_{\mathrm{d}}$ decrease with increasing 


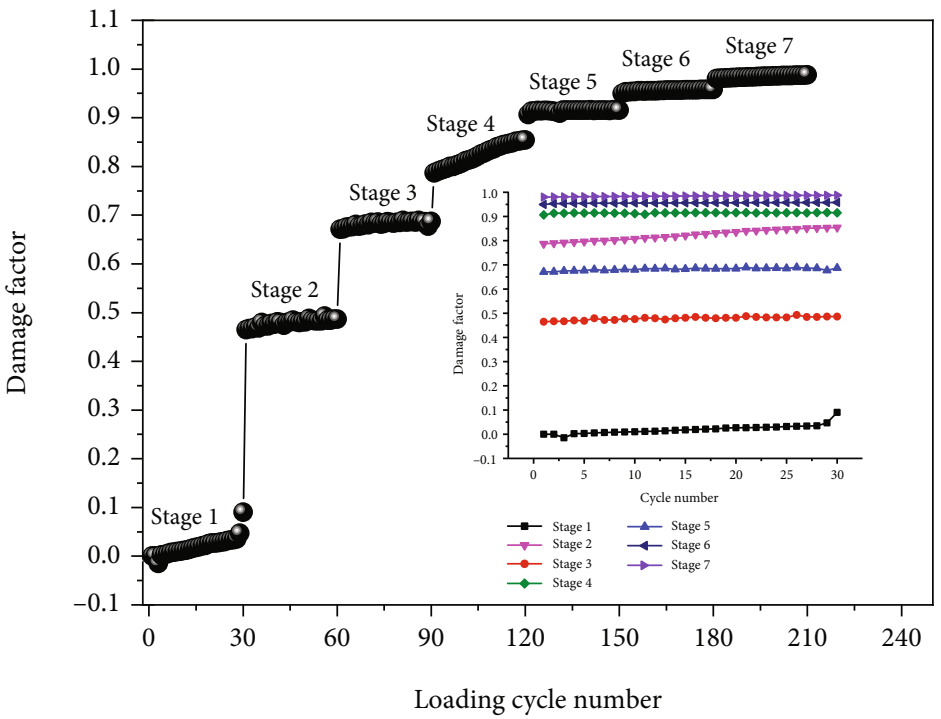

(a)

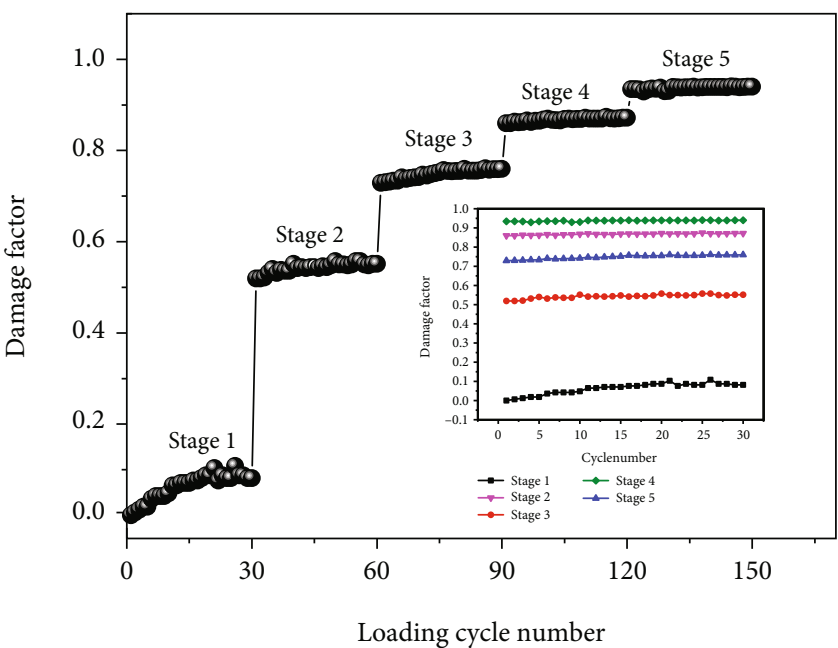

(b)

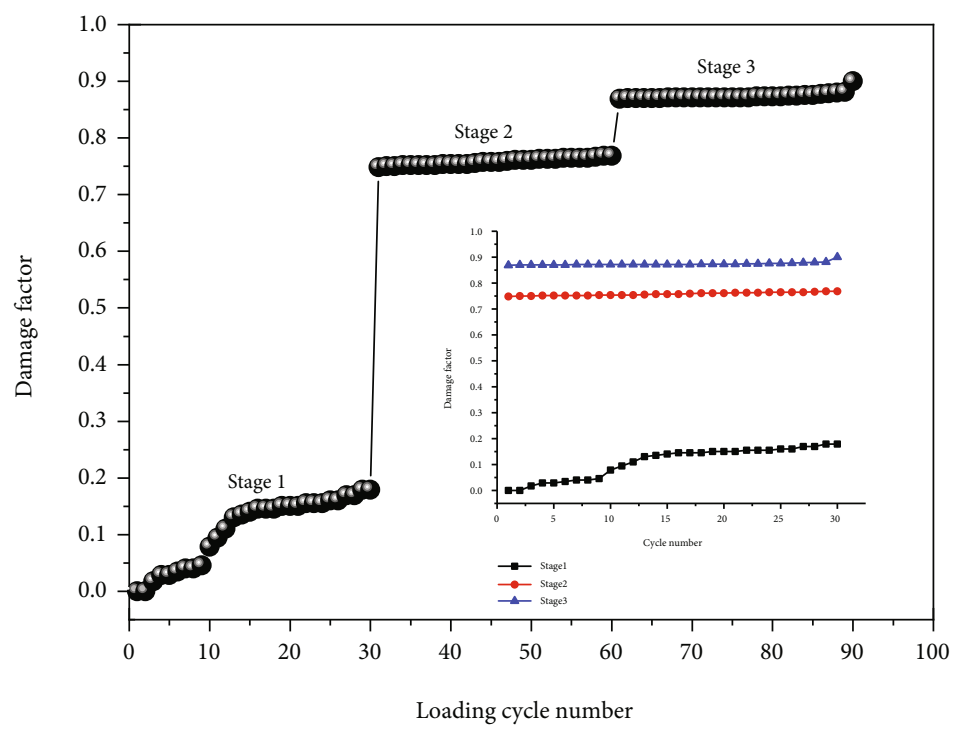

(c)

Figure 7: Continued. 


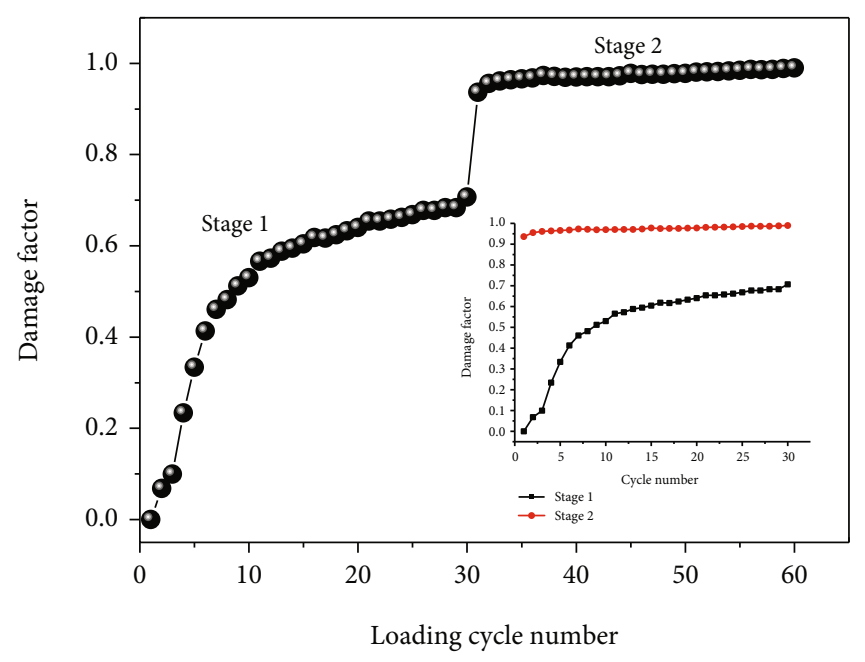

(d)

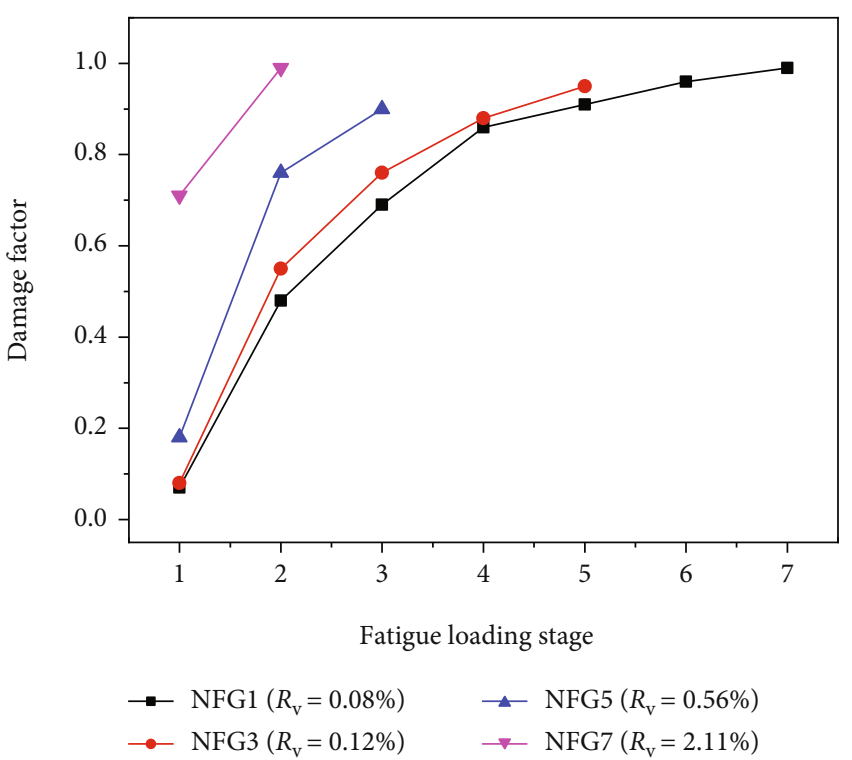

(e)

FIgURE 7: Plots of the damage evolution for the tested granite samples with different natural fracture volume ratios.

natural fracture volume and they obey exponential relations with good correlation.

It can be seen that energy dissipation and release during fatigue loading are not only related to the number of cycles but also related to the loading level. The relationship between strain energy and upper limit axial stress of granite under multistage loading is shown in Figure 9. The experimental data of total energy density $U$, elastic energy density $U_{\mathrm{e}}$, and total energy density $U_{\mathrm{d}}$ of each sample were fitted. The fitting results show that, although the natural fracture volume is different, $U, U_{\mathrm{e}}$, and $U_{\mathrm{d}}$ increase with the increase of the upper limit of axial stress under each fatigue load. In addition, an obvious nonlinear growth trend was observed, and the data were fitted using quadratic function. The fitting results show high correction, as presented in Table 1.

\section{Discussions}

Rock containing natural fracture subjected to fatigue loading conditions was conducted in this work. The macroscopic failure pattern is controlled by its internal mesoscopic structures, such as microcracks, pores, interbeds, joint, and flaws, [35-38]. Unlike previous studies, since sinusoidal signals may be more representative of stress waves generated during blasting or earthquakes than uniaxial and triaxial loading of rocks [24], in order to better simulate the stress perturbation effects during open-air slope mining, this paper fatigue loads granite containing natural fractures, and cyclic stresses are applied in a sinusoidal pattern. The macroscopic stress-strain curves show that the initial damage degree (i.e., natural fracture volume) has a significant effect on fatigue strength and deformation. The rock enters the volume expansion phase during fatigue loading, and for the large natural fracture volume, the fracture leading to the rock in the stress increase phase is due to the cumulative effect of the damage effect in the fatigue loading phase, and the fatigue life of the rock decreases with the increase of the natural fracture volume. Due to the preexistence of natural fracture, a large plastic deformation occurs during fatigue loading, and the evolution of the stress hysteresis loop indicates the evolutionary characteristics of plastic deformation. In this work, dynamic elastic modulus and damping ratio are used to describe the evolution of the stress hysteresis loop, and it is found that the dynamic elastic modulus and damping ratio gradually decrease with increasing loading cycles. These changes in dynamic indices are influenced by natural cracks.

The energy conversion analysis further reveals the fracture evolution mechanism. The input energy is composed of elastic energy and dissipated energy. The dissipated energy is mostly used to stimulate the preexisting natural fractures. Shearing and sliding along the natural fracture consume most of the energy; ratio of energy consumption is the largest for a sample with relatively high natural fracture volume ratio. The energy evolution in this work is different for intact rock without natural fracture or rock with artificial flaws. Frictions between the natural fractures also consume a part of energy. The increasing rate of elastic energy is faster than the dissipated energy, implying that rock has a certain strength reservation although with natural fractures. However, the capacity of energy storage is weaker than intact rock. These results indicate that larger deformation may occur for naturally fractured rock mass, and geological disaster (e.g., landslide and collapse) is prone to occur for this kind of rock mass. This phenomenon has been confirmed by the previous studies $[39,40]$. The increment of dissipated energy is first steady and then abrupt, and increasing rate becomes larger near at the last fatigue loading stage; this is influenced by the natural fracture. The evolution characteristics of the dissipated energy may be helpful to early warning of rock disasters. The final crack network pattern is the external reflection 

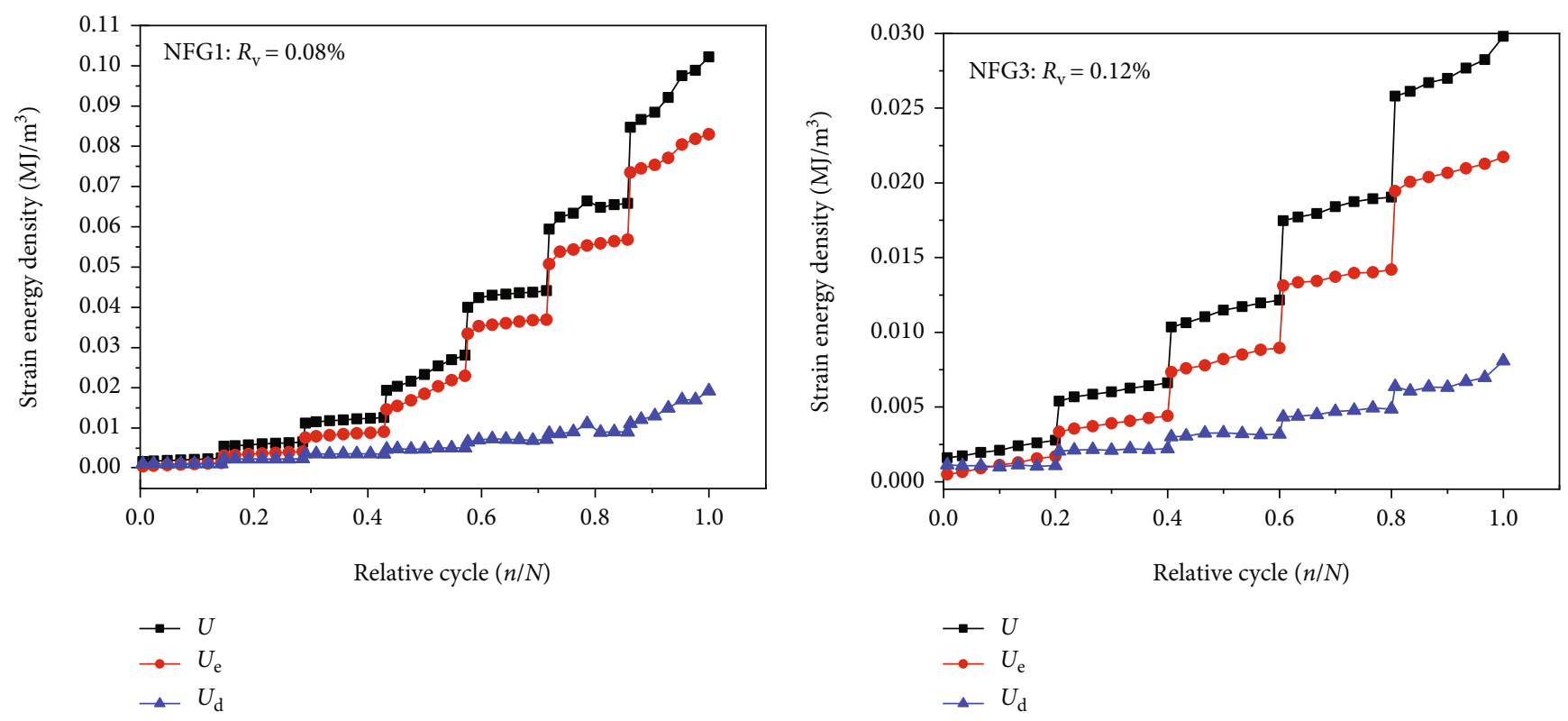

(a)
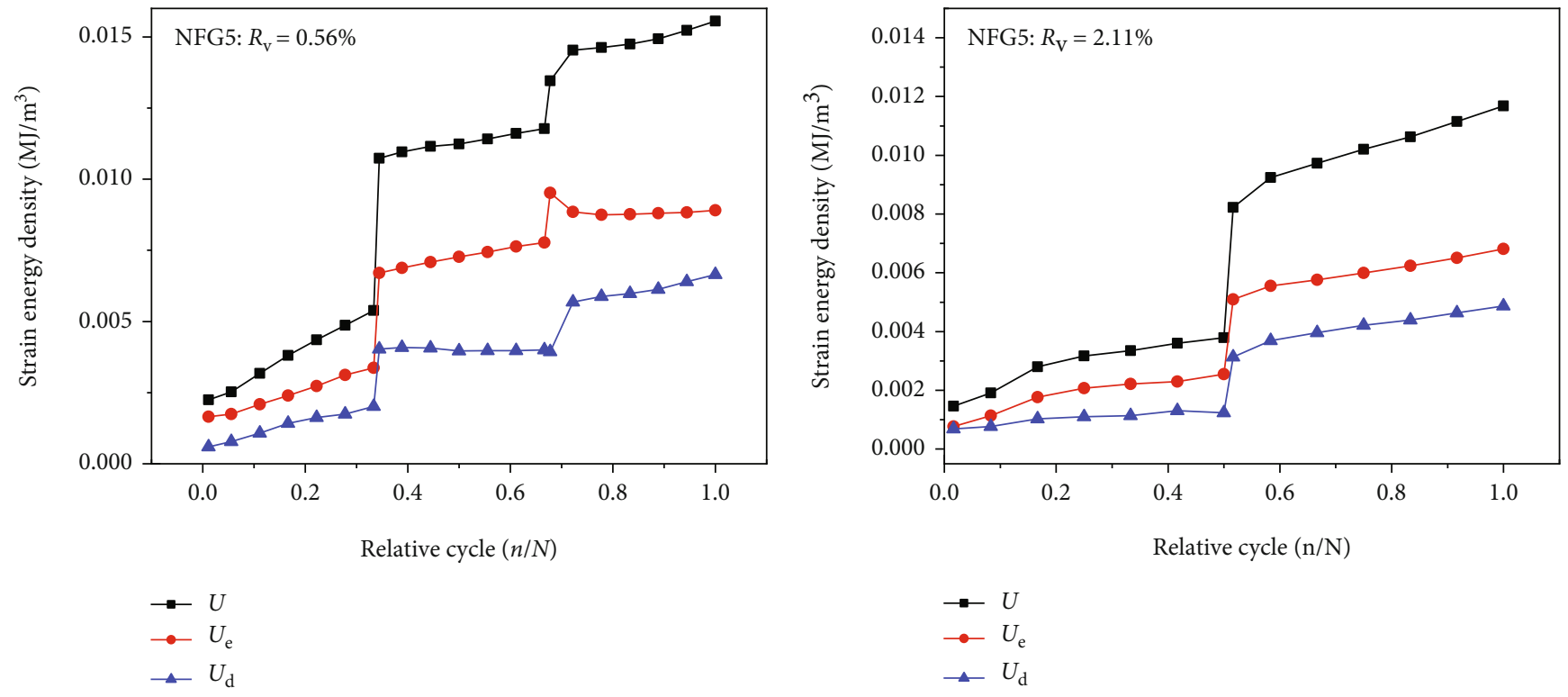

(c)

(d)

Figure 8: Continued. 


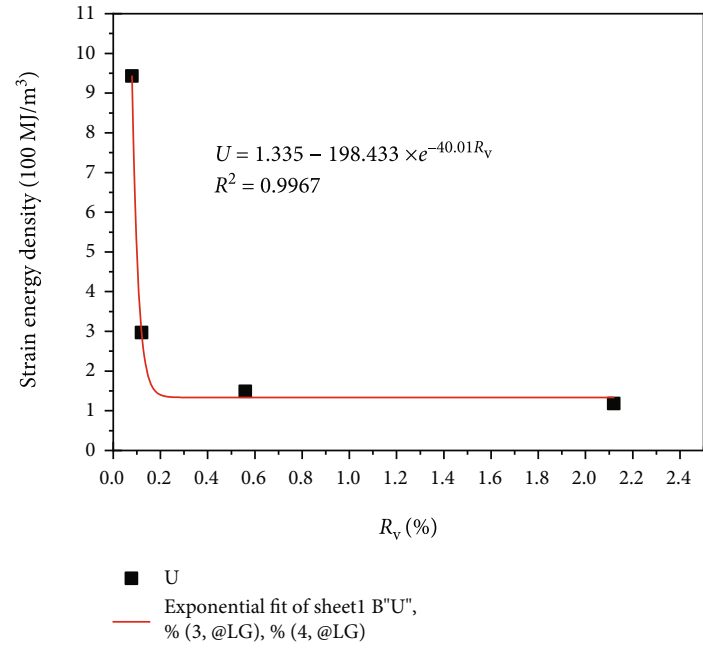

(e)

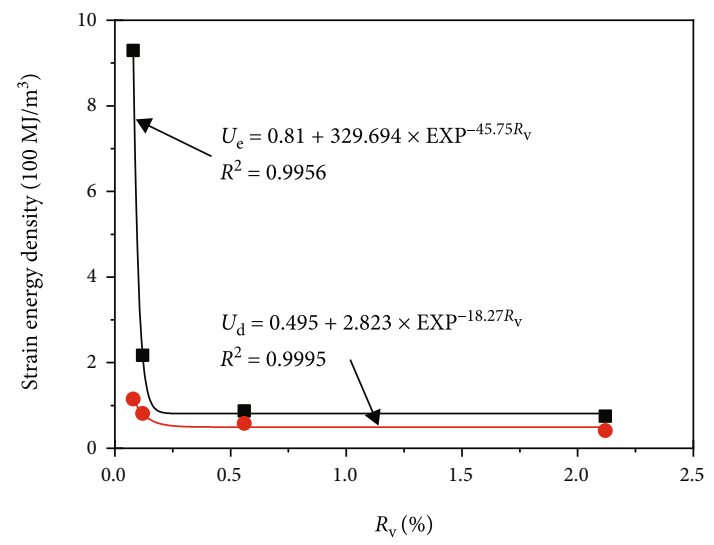

- $\mathrm{U}_{\mathrm{e}} \quad$ Exponential fit of sheet $\mathrm{C}$ " $\mathrm{U}_{\mathrm{e}}$ "

- $\mathrm{U}_{\mathrm{d}} \quad$ Exponential fit of sheet1 $\mathrm{D}^{\prime \prime} \mathrm{U}_{\mathrm{d}}$

(f)

Figure 8: Depiction of the evolution of $U, U_{\mathrm{e}}, U_{\mathrm{d}}$, and relative cycle for granite having different natural fracture volumes.
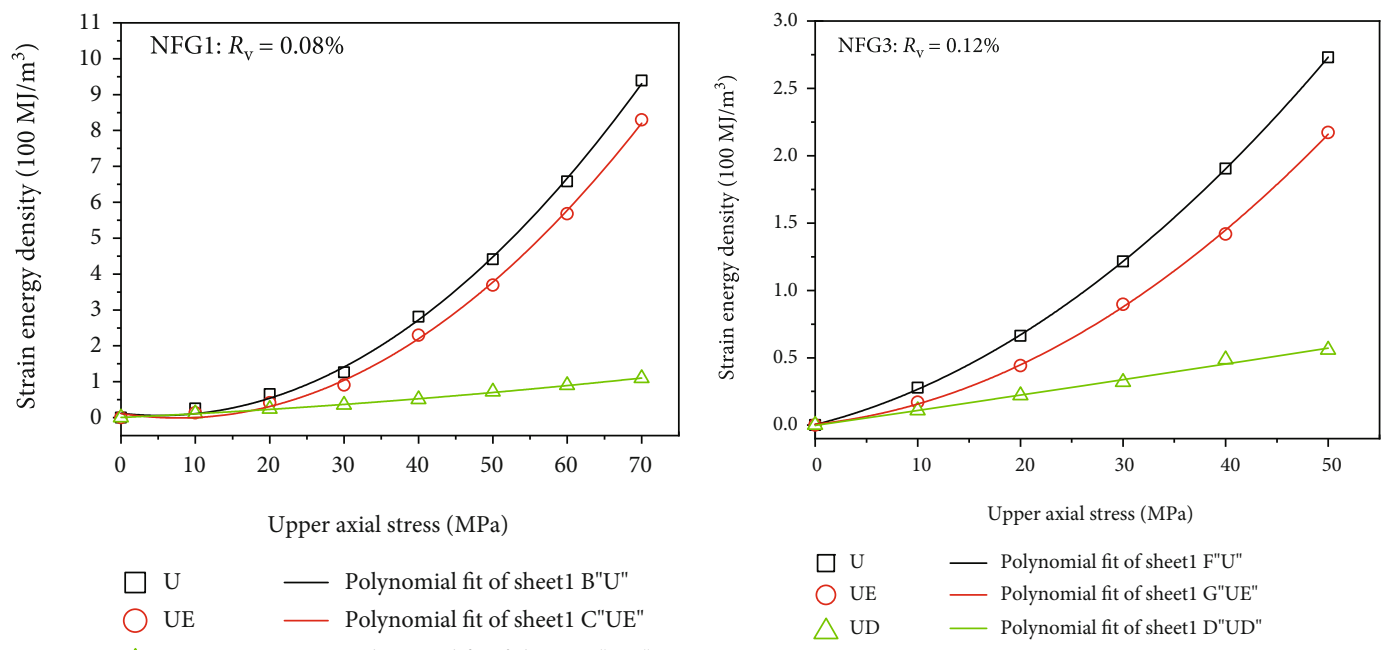

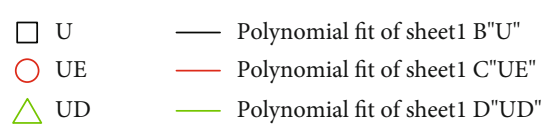

(a)

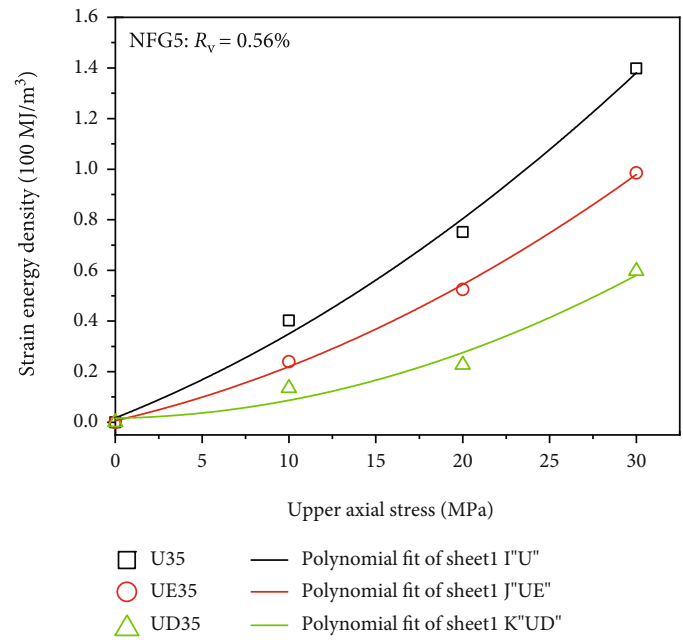

(c)

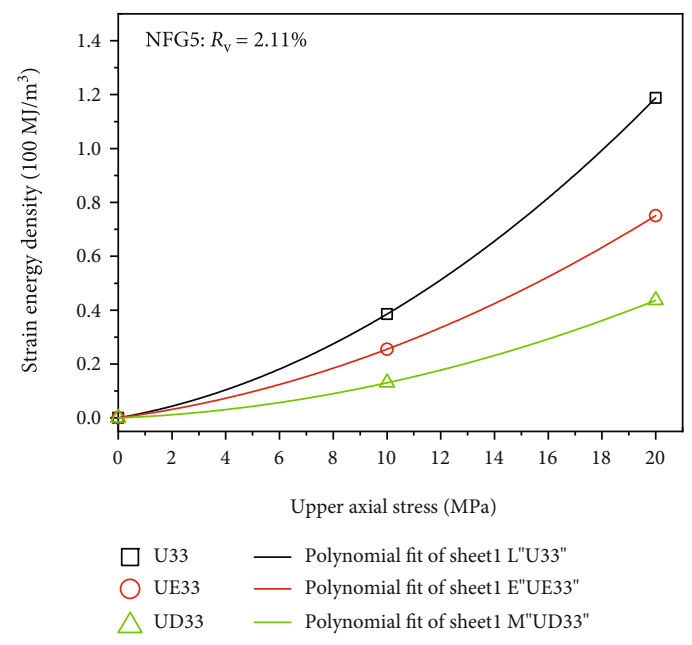

(d)

Figure 9: Evolution of the total strain energy, elastic energy, and dissipated energy with the upper axial stress at the last loading cycle of each stage. (a-d) The natural fracture volume is $0.08 \%, 0.12 \%, 0.56 \%$, and $2.11 \%$, respectively. 
TABLE 1: Fitting relationships for $U, U_{\mathrm{e}}, U_{\mathrm{d}}$, and the upper stress $\sigma$ during the whole test.

\begin{tabular}{|c|c|c|c|c|}
\hline $\begin{array}{l}\text { Sample } \\
\text { ID }\end{array}$ & $\begin{array}{c}\text { Initial damage degree } \\
(\%)\end{array}$ & $\begin{array}{l}\text { Type of strain energy } \\
(\times 100)\end{array}$ & Fitting function & Correlation coefficient $\left(R^{2}\right)$ \\
\hline \multirow{3}{*}{ NFG1 } & \multirow{3}{*}{$0.08 \%$} & $U$ & $U=0.1207-0.02307 \sigma+0.0022 \sigma^{2}$ & 0.9983 \\
\hline & & $U_{\mathrm{e}}$ & $U_{\mathrm{e}}=0.1163-0.3255 \sigma+0.00212 \sigma^{2}$ & 0.9978 \\
\hline & & $U_{\mathrm{d}}$ & $U_{\mathrm{d}}=0.00441+0.00948 \sigma+8.892 E-5 \sigma^{2}$ & 0.9985 \\
\hline \multirow{3}{*}{ NFG3 } & \multirow{3}{*}{$0.12 \%$} & $U$ & $U=0.00406+0.01915 \sigma+7.098 E-4 \sigma^{2}$ & 0.9994 \\
\hline & & $U_{\mathrm{e}}$ & $U_{\mathrm{e}}=0.00711+0.00798 \sigma+7.016 E-4 \sigma^{2}$ & 0.9921 \\
\hline & & $U_{\mathrm{d}}$ & $U_{\mathrm{d}}=-0.00305+0.01117 \sigma+6.375 E-5 \sigma^{2}$ & 0.9887 \\
\hline \multirow{3}{*}{ NFG5 } & \multirow{3}{*}{$0.56 \%$} & $U$ & $U=0.0174+0.02714 \sigma+6.1 E-4 \sigma^{2}$ & 0.9827 \\
\hline & & $U_{\mathrm{e}}$ & $U_{\mathrm{e}}=0.00635+0.01583 \sigma+5.525 E-4 \sigma^{2}$ & 0.9955 \\
\hline & & $U_{\mathrm{d}}$ & $U_{\mathrm{d}}=0.01605+0.0012 \sigma+5.875 E-5 \sigma^{2}$ & 0.9214 \\
\hline \multirow{3}{*}{ NFG7 } & \multirow{3}{*}{$2.11 \%$} & $U$ & $U=0.02905 \sigma+0.00341 \sigma^{2}$ & 0.9694 \\
\hline & & $U_{\mathrm{e}}$ & $U_{\mathrm{e}}=0.02995 \sigma+0.00267 \sigma^{2}$ & 0.9798 \\
\hline & & $U_{\mathrm{d}}$ & $U_{\mathrm{d}}=-9 E-4 \sigma+7.4 E-4 \sigma^{2}$ & 0.9862 \\
\hline
\end{tabular}

of energy dissipation and releases. Shearing along natural fracture consumes relatively small proportion of energy than formation of new cracks. The crack pattern provides us insight about the mesoscopic fracturing process of rock; the interactions between the preexisting natural fracture and the newly formed crack can be clearly observed from the CT images.

\section{Conclusions}

The multistage uniaxial fatigue loading tests of granite samples with natural fractures were carried out in laboratory. The effects of natural fractures on deformation characteristics, hysteretic loop pattern, damage evolution, energy evolution, and final failure pattern were revealed by macroscopic stress-strain response description. The following conclusions can be drawn from this study:

(1) Rock fatigue deformation is caused mainly by the compaction and stimulation of the preexisting natural fractures. Volumetric deformation suddenly increases from a certain fatigue loading stage, indicating the acceleration of rock damage. Rock damage at the stress-increasing stage is much more severe than the fatigue loading stage

(2) Evolution of hysteresis loop is characterized by the changes of dynamic elastic modulus and damping ratio. The overall decrement of dynamic elastic modulus indicates the stiffness degradation of granite samples, and the overall decrement of damping ratio indicates the increment of energy loss. The changes of these two parameters are closely related to the evolution of natural fractures

(3) The energy dissipation and release characteristics are strongly affected by natural fractures. The total input energy, elastic energy, and dissipated energy all decrease with the increase of loading cycles. The dissipated energy is used to activate existing natural fractures and create new ones. The dissipation energy increases rapidly near the failure of the sample, which indicates that the dissipation energy can be used to predict the instability of rock mass structure

\section{Data Availability}

The experimental data used to support the findings of this study are included within the article.

\section{Conflicts of Interest}

The authors declare no conflict of interest.

\section{Acknowledgments}

This study was supported by the National Key Technologies Research \& Development Program (2018YFC0808402) and the Fundamental Research Funds for the Central Universities (FRF-TP-20-004A2).

\section{References}

[1] Y. Wang, W. K. Feng, R. L. Hu, and C. H. Li, "Fracture evolution and energy characteristics during marble failure under triaxial fatigue cyclic and confining pressure unloading (FCCPU) conditions," Rock Mechanics and Rock Engineering, vol. 23, pp. 1-20, 2020.

[2] C. Zhu, M. C. He, M. Karakus, X. B. Cui, and Z. G. Tao, "Investigating toppling failure mechanism of anti-dip layered slope due to excavation by physical modelling," Rock Mechanics and Rock Engineering, vol. 53, no. 11, pp. 5029-5050, 2020.

[3] Z. Hossain, B. Indraratna, F. Darve, and P. K. Thakur, "DEM analysis of angular ballast breakage under cyclic loading," 
Geomechanics and Geoengineering, vol. 2, no. 3, pp. 175-181, 2007.

[4] J. Fan, J. Chen, D. Jiang, S. Ren, and J. Wu, "Fatigue properties of rock salt subjected to interval cyclic pressure," International Journal of Fatigue, vol. 90, pp. 109-115, 2016.

[5] J. Fan, D. Jiang, J. Chen, W. Liu, W. T. Ngaha, and J. Chen, "Fatigue performance of ordinary concrete under discontinuous cyclic loading," Construction and Building Materials, vol. 166, pp. 974-981, 2018.

[6] A. S. Gupta and K. S. Rao, "Weathering effects on the strength and deformational behaviour of crystalline rocks under uniaxial compression state," Engineering Geology, vol. 56, no. 3-4, pp. 257-274, 2000.

[7] Y. Wang, W. K. Feng, and C. H. Li, "On anisotropic fracture and energy evolution of marble subjected to triaxial fatigue cyclic-confining pressure unloading conditions," International Journal of Fatigue, vol. 134, article 105524, 2020.

[8] Y. Wang, C. Li, J. Han, and H. Wang, "Mechanical behaviours of granite containing two flaws under uniaxial increasingamplitude fatigue loading conditions: an insight into fracture evolution analyses," Fatigue \& Fracture of Engineering Materials \& Structures, vol. 43, no. 9, pp. 2055-2070, 2020.

[9] Y. Wang, C. H. Li, H. Liu, and J. Q. Han, "Fracture failure analysis of freeze-thawed granite containing natural fracture under uniaxial multi-level cyclic loads," Theoretical and Applied Fracture Mechanics, vol. 110, article 102782, 2020.

[10] Y. Wang, B. Zhang, S. H. Gao, and C. H. Li, "Investigation on the effect of freeze-thaw on fracture mode classification in marble subjected to multi-level cyclic loads," Theoretical and Applied Fracture Mechanics, vol. 111, Article ID 102847, 2021.

[11] J. Q. Xiao, D. X. Ding, F. L. Jiang, and G. Xu, "Fatigue damage variable and evolution of rock subjected to cyclic loading," International Journal of Rock Mechanics \& Mining Sciences, vol. 47, no. 3, pp. 461-468, 2010.

[12] Y. Wang, S. H. Gao, C. H. Li, and J. Q. Han, "Investigation on fracture behaviors and damage evolution modeling of freezethawed marble subjected to increasing- amplitude cyclic loads," Theoretical and Applied Fracture Mechanics, vol. 109, article 102679, 2020.

[13] Y. Wang, S. H. Gao, C. H. Li, and J. Q. Han, "Energy dissipation and damage evolution for dynamic fracture of marble subjected to freeze-thaw and multiple level compressive fatigue loading," International Journal of Fatigue, vol. 142, article 105927, 2020.

[14] Y. Wang, D. Liu, J. Han, C. Li, and H. Liu, "Effect of fatigue loading-confining stress unloading rate on marble mechanical behaviors: an insight into fracture evolution analyses," Journal of Rock Mechanics and Geotechnical Engineering, vol. 12, no. 6, pp. 1249-1262, 2020.

[15] Y. Wang, S. Gao, D. Liu, and C. Li, "Anisotropic fatigue behaviour of interbeded marble subjected to uniaxial cyclic compressive loads," Fatigue \& Fracture of Engineering Materials \& Structures, vol. 43, no. 6, pp. 1170-1183, 2020.

[16] K. Lupogo, Characterization of Blast Damage in Rock Slopes: An Integrated Field-Numerical Modeling Approach, Ph.D thesis. Simon Fraser University, British Columbia, Canada, 2017.

[17] B. Mohanty and S. Chung, "Production blasting and slope stability," in Proceedings of the International Symposium on Geotechnical Stability in Surface Mining, pp. 133-140, CANMET, Calgary, Alberta, Canada, 1986.
[18] Y. Wang, H. Meng, and D. Long, "Experimental investigation of fatigue crack propagation in interbedded marble under multilevel cyclic uniaxial compressive loads," Fatigue \& Fracture of Engineering Materials \& Structures, vol. 35, 2020.

[19] W. Liu, S. Zhang, and B. Sun, "Energy evolution of rock under different stress paths and establishment of a statistical damage model," KSCE Journal of Civil Engineering, vol. 23, no. 10, pp. 4274-4287, 2019.

[20] Z. Zhao, W. Ma, X. Fu, and J. Yuan, "Energy theory and application of rocks," Arabian Journal of Geosciences, vol. 12, no. 15, pp. 1-26, 2019.

[21] P. Hai, H. Lijun, Z. Mingwei, M. Qingbin, and Z. Zhizhen, "Experimental research on rock energy evolution under uniaxial cyclic loading and unloading compression," Geotechnical Testing Journal, vol. 41, no. 4, pp. 717-729, 2018.

[22] Z. Zhao, H. Zhang, and C. Tang, "Numerical study on breakage and shear behavior of intermittent rock joints," Soil and Rock Behavior and Modeling, vol. 86, pp. 248-253, 2006.

[23] K. Zhang, Y. Chen, and W. Fan, "Influence of intermittent artificial crack density on shear fracturing and fractal behavior of rock bridges: experimental and numerical studies," Rock Mechanics and Rock Engineering, vol. 53, no. 2, pp. 553-568, 2020.

[24] Y. L. Bai, Z. W. Yan, J. F. Jia, T. Ozbakkaloglu, and Y. Liu, "Dynamic compressive behavior of concrete confined with unidirectional natural flax FRP based on SHPB tests," Composite Structures, vol. 259, article 113233, 2020.

[25] Q. Z. Wang, J. R. Yang, C. G. Zhang et al., "Determination of dynamic crack initiation and propagation toughness of a rock using a hybrid experimental-numerical approach," Journal of Engineering Mechanics, vol. 142, no. 12, article 04016097, 2016.

[26] Z. Wang, H. Li, and J. Wang, "Experimental study on mechanical and energy properties of granite under dynamic triaxial condition," Geotechnical Testing Journal, vol. 41, no. 6, pp. 1063-1075, 2018.

[27] R. H. C. Wong, K. T. Chau, C. A. Tang, and P. Lin, “Analysis of crack coalescence in rock-like materials containing three flaws- part I: experimental approach," International Journal of Rock Mechanics and Mining Sciences, vol. 38, no. 7, pp. 909-924, 2001.

[28] T. Li, X. Pei, J. Guo, M. Meng, and R. Huang, "An energybased fatigue damage model for sandstone subjected to cyclic loading," Rock Mechanics and Rock Engineering, vol. 53, no. 11, pp. 5069-5079, 2020.

[29] N. Erarslan and D. J. Williams, "Investigating the effect of cyclic loading on the indirect tensile strength of rocks," Rock Mechanics and Rock Engineering, vol. 45, no. 3, pp. 327-340, 2012.

[30] Y. Wang, Y. Z. Hu, and S. H. Gao, "Dynamic mechanical behaviors of interbedded marble subjected to multi-level uniaxial compressive cyclic loading conditions: an insight into fracture evolution analysis," Engineering Fracture Mechanics, vol. 241, article 107410, 2020.

[31] F. Lamas-Lopez, "Field and laboratory investigation on the dynamic behavior of conventional railway track-bed materials in the context of traffic upgrade," Ph.D. thesis, Ecole Nationale des Ponts et Chaussees, Universite Paris-Est, 2016.

[32] K. Fuenkajorn and D. Phueakphum, "Effects of cyclic loading on mechanical properties of Maha Sarakham salt," Engineering Geology, vol. 112, no. 1-4, pp. 43-52, 2010. 
[33] R. Song, Y. Bai, J. P. Zhang, D. Jiang, and C. Yang, "Experimental investigation of the fatigue properties of salt rock," International Journal of Rock Mechanics and Mining Sciences, vol. 64, pp. 68-72, 2013.

[34] R. Solecki and R. J. Conant, Advanced Mechanics of Materials, Oxford University Press, London, 2003.

[35] C. Zhu, Z. Yan, Y. Lin, F. Xiong, and Z. Tao, "Design and application of a monitoring system for a deep railway foundation pit project," IEEE Access, vol. 7, pp. 107591-107601, 2019.

[36] Y. Wang, W. K. Feng, H. J. Wang, C. H. Li, and Z. Q. Hou, "Rock bridge fracturing characteristics in granite induced by freeze-thaw and uniaxial deformation revealed by AE monitoring and post-test CT scanning," Cold Regions Science and Technology, vol. 177, article 103115, 2020.

[37] Z. Li, S. Liu, W. Ren, J. Fang, Q. Zhu, and Z. Dun, “Multiscale laboratory study and numerical analysis of water-weakening effect on shale," Advances in Materials Science and Engineering, vol. 2020, Article ID 5263431, 14 pages, 2020.

[38] Q. Meng, H. Wang, M. Cai, W. Xu, X. Zhuang, and T. Rabczuk, "Three-dimensional mesoscale computational modeling of soil-rock mixtures with concave particles," Engineering Geology, vol. 277, article 105802, 2020.

[39] C. Zhu, X. Xu, W. Liu et al., "Softening damage analysis of gypsum rock with water immersion time based on laboratory experiment," IEEE Access, vol. 7, pp. 125575-125585, 2019.

[40] Z. Li, H. Liu, Z. Dun, L. Ren, and J. Fang, "Grouting effect on rock fracture using shear and seepage assessment," Construction and Building Materials, vol. 242, article 118131, 2020. 